University of Massachusetts Amherst

ScholarWorks@UMass Amherst

Masters Theses 1911 - February 2014

2004

\title{
The impact of background television on parent-child interaction.
}

Heather L. Kirkorian

University of Massachusetts Amherst

Follow this and additional works at: https://scholarworks.umass.edu/theses

Kirkorian, Heather L., "The impact of background television on parent-child interaction." (2004). Masters Theses 1911 - February 2014. 2420.

Retrieved from https://scholarworks.umass.edu/theses/2420

This thesis is brought to you for free and open access by ScholarWorks@UMass Amherst. It has been accepted for inclusion in Masters Theses 1911 - February 2014 by an authorized administrator of ScholarWorks@UMass Amherst. For more information, please contact scholarworks@library.umass.edu. 
THE IMPACT OF BACKGROUND TELEVISION ON

PARENT-CHILD INTERACTION

A Thesis Presented

by

HEATHER L. KIRKORIAN

Submitted to the Graduate School of the University of Massachusetts Amherst in partial fulfillment of the requirements for the degree of

\section{MASTER OF SCIENCE}

September 2004

Psychology 


\section{THE IMPACT OF BACKGROUND TELEVISION ON \\ PARENT-CHILD INTERACTION}

A Thesis Presented

by

HEATHER L. KIRKORIAN

Approved as to style and content by:

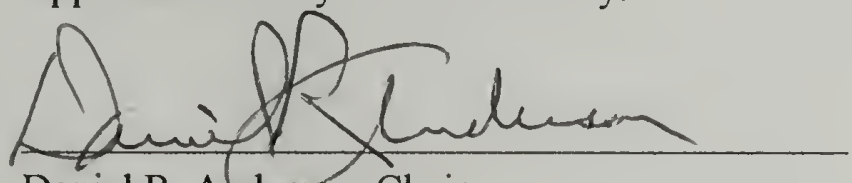

Daniel R. Anderson, Chair
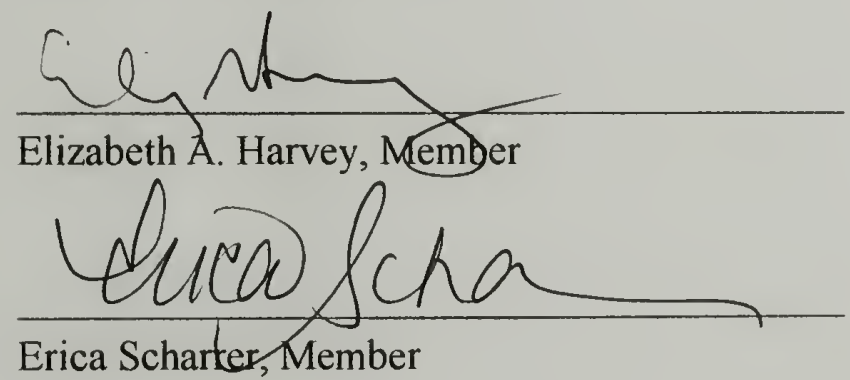

Theuder a. hovald

Melinda A. Novak, Department Chair

Department of Psychology 


\section{CONTENTS}

LIST OF TABLES

LIST OF FIGURES

CHAPTER

1. INTRODUCTION

Literature Review

Television and Development....................................................... 2

Children's Exposure to Background Television ....................................... 2

Social Environment and Parent-Child Interaction .............................. 3

Parent Responsiveness ............................................................... 6

Parent Response Strategy ...................................................... 9

Attention-Directing Strategy ....................................................... 10

Parent Involvement ............................................................... 13

Television as Background Noise .................................................. 13

Television, Distraction, and Distractibility .................................... 14

Overview of the Present Study ............................................................ 15

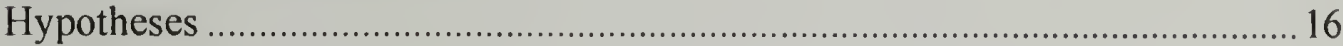

Overall Parent Interaction and Responsiveness ................................. 16

Quality of Parent Interactions....................................................... 16

Child Behavior ......................................................................... 17

Child Age and Sex....................................................................... 17

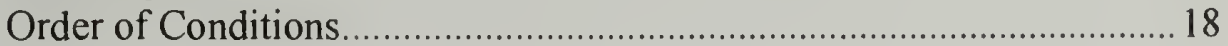

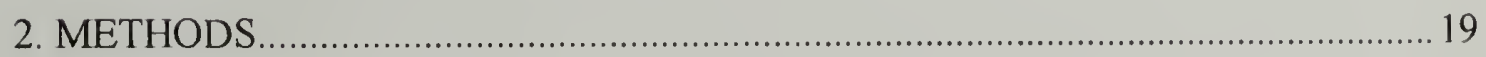

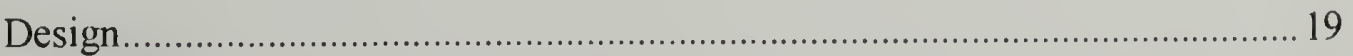

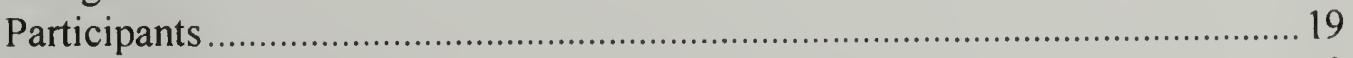

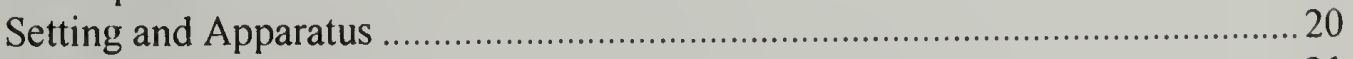

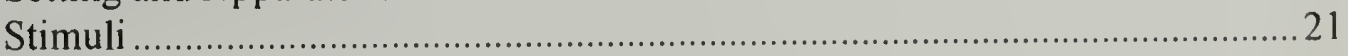

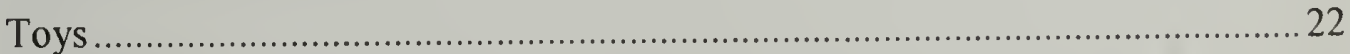

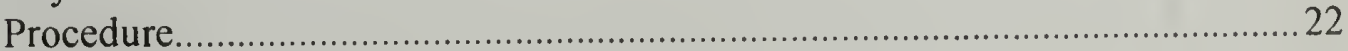

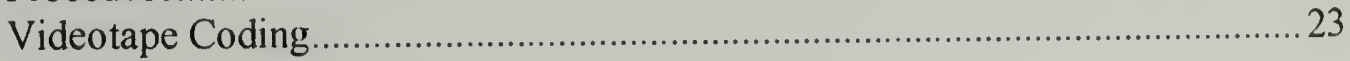

Parent Response Type ............................................................ 24

Parent Response Strategy ......................................................... 25

Attention-Directing Strategy ................................................. 26 
Parent Responsiveness

Child Behavior Type.

27

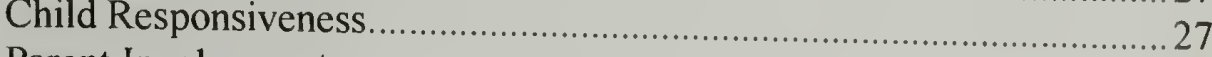

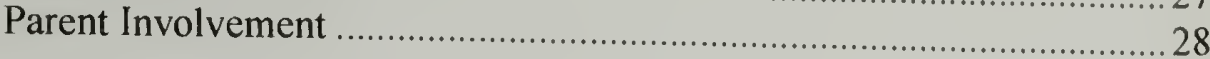

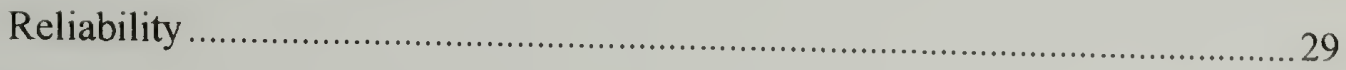

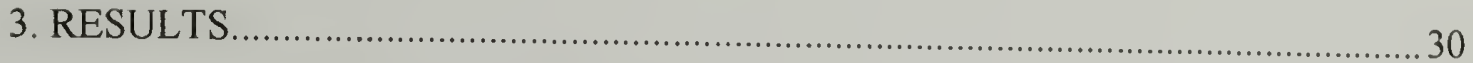

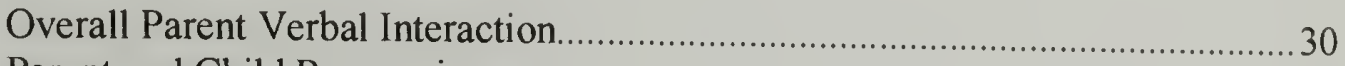

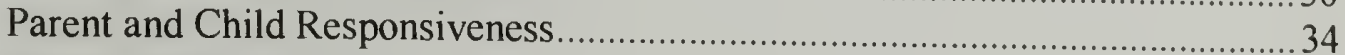

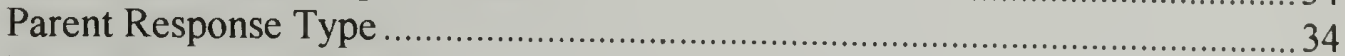

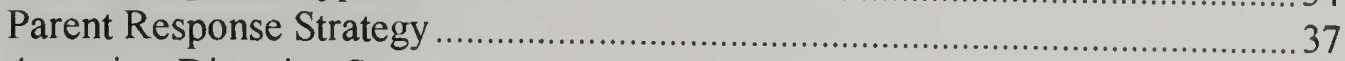

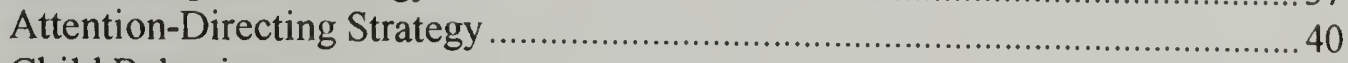

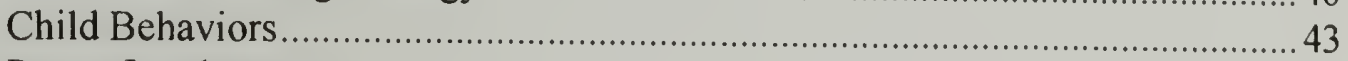

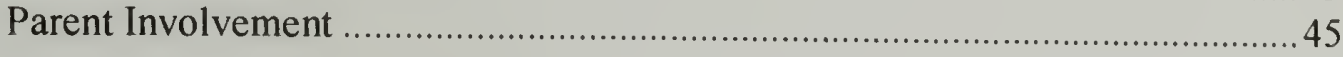

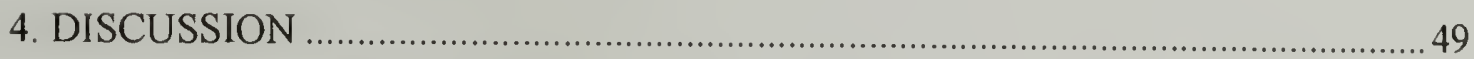

Overall Parent Interaction and Responsiveness ...............................................4 49

Quality of Parent Interactions........................................................................ 51

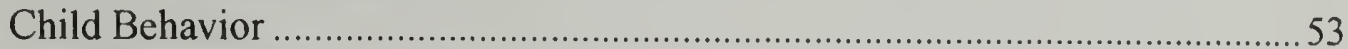

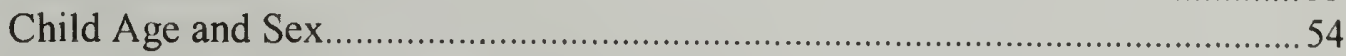

Impact of Background Television over Time.....................................................55

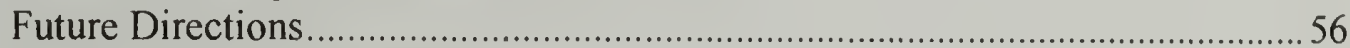

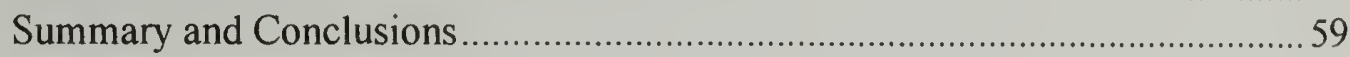

\section{APPENDICES}

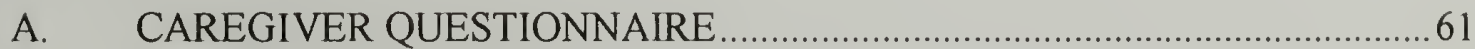

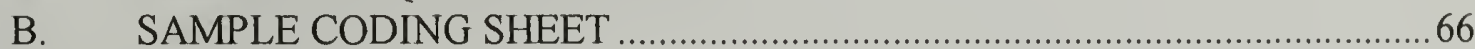

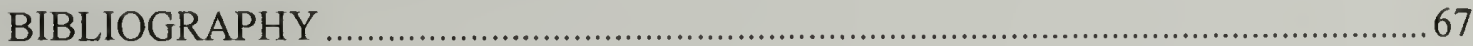




\section{LIST OF TABLES}

Table

1. Descriptive statistics for the average proportion of intervals containing each original target behavior and probability of responding for parents and children

2. Proportion of intervals containing each of the final combined dependent measures, percent of object play that was active, and probability of responding for both parent and child

3. Mean proportion of intervals containing each response type with standard errors in the No TV and TV conditions and percent change with television.

4. Mean proportion of intervals containing each response type with standard errors for 24- and 36-month-olds in the No TV and TV conditions and percent change with television

5. Mean proportion of intervals containing each response strategy with standard errors in the No TV and TV conditions and percent change with television.

6. Mean proportion of intervals containing suggestive behaviors in the No TV and TV conditions by test order and percent change with television.

7. Mean proportion of intervals containing each attention-directing strategy with standard errors in the No TV and TV conditions and percent change with television.

8. Mean proportion of intervals for 24- and 36-month-olds containing each attention-directing behavior with standard errors in the No TV and TV conditions and percent change with television.

9. Mean proportion of intervals containing each child behavior type with standard errors in the No TV and TV conditions and percent change with television.

10. Mean proportion of time spent at each involvement level and proportion of object play spent actively involved with standard errors in the No TV and TV conditions with percent change.

11. Mean proportion of time spent actively involved in object play in the No TV and TV conditions by test order and percent change with television 


\section{LIST OF FIGURES}

Figure

1. Proportion of intervals containing any parent verbal interaction with TV regressed on interactions without TV

2. Proportion of intervals containing each response type in the No TV and TV conditions.

3. Proportion of intervals containing each response strategy in the No TV and TV conditions.

4. Proportion of intervals containing each attention-directing strategy in the No TV and TV conditions.

5. Proportion of intervals containing child social behavior and self-directed speech in the No TV and TV conditions

6. Proportion of intervals containing each of the original five levels of involvement in the No TV and TV conditions.

7. Proportion of total time spent interacting or engaged in object play in the No TV and TV conditions. 


\section{CHAPTER 1}

\section{INTRODUCTION}

\section{$\underline{\text { Literature Review }}$}

According to the American Academy of Pediatrics, preschoolers should watch no more than one hour of television per day, and infants and toddlers under two years of age should not be exposed to any screen media at all (American Academy of Pediatrics, 1999). Despite this recommendation, children zero to three years of age are exposed to substantial amounts of television at home. Very young children currently watch an hour of television daily. More importantly for present purposes, forty percent of children zero to three years of age live in homes that caretakers characterize as having a television on "most of the time" or "always", even if no one is watching (Kaiser Family Foundation, 2003).

Some field studies suggest that early exposure to television is associated with negative outcomes (e.g., Carew, 1980; Nelson, 1973; Christakis, Zimmerman, DiGiuseppe, \& McCarty, 2004). One way that television may negatively affect development is by interfering with social interactions between parents and their children. This study investigates the impact of background television on parent-child interaction. The literature review begins with a summary of children's attention and exposure to television, followed by a review of relevant parent-child interaction literature, and concludes with a description of how background television may affect parent-child interaction. The introduction finishes with an overview of the study and hypotheses. 


\section{Television and Development}

Relatively little is known about the effect of television on early development, zero to three years. Some studies suggest a negative impact of early exposure to television in the home (e.g., Carew, 1980; Nelson, 1973; Christakis et al, 2004). Others studies, however, demonstrate that television can be associated with positive outcomes (Carew, 1980; Anderson, Schmitt, Huston, Linebarger, \& Wright, 2001; Wright et al, 2001). It is important to note that the former studies were conducted before television shows designed as educational, foreground programming for children were common. Therefore, the television children were likely exposed to in these studies was as background television designed for an older audience. More recent studies of foreground television suggest that content is important and that programming with an informative and educational curriculum can result in positive developmental outcomes (e.g., Wright et al, 2001).

\section{Children's Exposure to Background Television}

Television is on an average of six hours a day in American homes (Kaiser Family Foundation, 1999), yet very young children are reported to watch only one hour per day (Kaiser Family Foundation, 2003), suggesting that the television is usually on in the background for these children. Similarly, home-viewing studies have found that although the television is on during much of the observed time, young children pay relatively little visual attention to it. For instance, Clarke-Stewart (1973) found that the television was on for more than half of the time spent observing in homes but infants in the first year and a half of life actively watched the television for less than $2 \%$ of their 
waking time each day. In another study by Nelson (1973) the television was on for more than four hours per day, but 18-month-old children only watched about one hour. Schmitt, Woolf, and Anderson (2003) examined data collected in 1980 and 1981 in a home-viewing study to find that two-year-old children were often in the room while parents and older siblings watched television, although they paid relatively low levels of attention to the television themselves.

Together these findings suggest that parents incidentally expose very young children to television by watching while their children are present. It is this exposure to television that is considered "background" (Anderson \& Evans, 2001). One way in which background television may affect development is by interfering with very young children's solitary play. Recent research supports this claim, finding that very young children exhibit shorter play episodes and less focused attention during object play in the presence of background television (Evans, Frankenfield, Pempek, Kirkorian, \& Anderson, 2004; Evans, Pempek, Kirkorian, Frankenfield, \& Anderson, 2004). Another way in which background television may influence development, however, is by interfering with parent-child interaction. Following is a summary of the relevant parent-child interaction literature and evidence supporting the hypothesis that background television may have a negative impact on this interaction.

\section{Social Environment and Parent-Child Interaction}

There is a vast literature examining environmental factors that affect cognitive and social development. In broad terms, a sensitive, stimulating, and otherwise highquality home is positively related to cognition, achievement, language, and social 
competence in children (National Institute of Child Health and Human Development, 2003). Among the most important influences in development are social interactions with family, peers, teachers, and others. Vygotsky (1978) coined the term "zone of proximal development" to describe the points in development where a child is able to successfully complete a particular task only in the presence of others within a social context. This stage is indicative of the child's potential in the presence of adults, peers, and other collaborators, rather than his or her independent problem-solving ability. The zone of proximal development predicts what the child will be able to do independently in the near future.

Perhaps not surprisingly, a great deal of the research that attempts to tease apart the social factors most influential to development focuses on parent-child interaction. Clarke-Stewart (1973) emphasized the importance of parents as mediators of the child's environment. Parents can help children encode information from the environment, allowing them to understand the world. When school-aged children explore a science exhibit with a parent, they demonstrate more overall exploration, examine more types of scientific evidence, and are more likely to utilize the most relevant evidence than when examining the exhibit alone or with peers (Crowley, Callanan, Jipson, \& Galco, 2001). Furthermore, most of the relevant discussion of evidence is initiated and guided by the parent during these interactions. In this example, parents supported scientific thinking by identifying strategies and encouraging the children's encoding of scientific evidence. Previous research has uncovered other specific benefits associated with parent-child interaction during object play. For instance, typically-developing children increase their levels of independent goal-directed play after a session of joint play with their mothers 
(Landry, Miller-Loncar, \& Swank, 1998) and young children exhibit more of higher qualitative levels of cognitive play when interacting with mothers than during solitary play (Alessandri, 1992).

Parental interaction may also be important in compensating for early individual differences in characteristics related to cognitive development. For instance, Henderson (1984) measured levels of exploration in young children during solitary play and divided the subjects into low- and high-exploratory groups. He then observed children during joint toy play with mothers. Children who demonstrated relatively low levels of exploration during solitary play increased their exploration with their mothers such that there were no group differences during joint play. Similarly, maternal interaction was found to increase focused attention in infants, particularly for those who demonstrated relatively low levels of focused attention during solitary object play (Lawson, Parinello, \& Ruff, 1992). When Henderson's (1984) study was replicated adding a condition in which the mother was present in the room but non-interactive, no differences were found between levels of exploration during this new condition and during solitary play, suggesting that maternal presence is not enough to encourage exploration in relatively low-exploratory children. Rather, children need collaborative interaction to compensate for individual differences.

In several studies, parental stimulation in particular is found to be important to development. Mothers' verbal stimulation (not just general auditory stimuli) was found to be the single best predictor of overall cognitive competence and language in children (Clarke-Stewart, 1973; Olson, Bates, \& Bayles, 1984) and maternal stimulation with objects was found to be the best predictor of play in the home (Clarke-Stewart, 1973). 
This holds true even when controlling for early competence, demonstrating that this is not the result of mothers responding to early individual differences in their children's ability (Olson, Bates, \& Bayles, 1984). The amount of verbal and object stimulation also appears to be related to children's language, emotional expression, skill with objects, and social development (Clarke-Stewart, 1973). Olson and colleagues (1984) even suggest that verbal stimulation alone may mediate socio-economic status as a predictor of child competence.

\section{Parent Responsiveness}

One aspect of parent-child interaction that has received a great deal of attention in the literature is that of parent responsiveness. Bornstein and Tamis-LeMonda (1989) define maternal responsiveness as "mother's prompt, contingent, and appropriate (not simply contiguous) behaviors" (p. 50). Although maternal responsiveness as it is defined here is held separately from non-contingent verbal stimulation, these researchers found that mothers who are more responsive to their infants also have shorter latencies in responding and stimulate their children more. Bornstein and TamisLeMonda (1989) propose several ways in which responsiveness may result in positive child outcomes. For instance, responsiveness may support self-regulation, thus influencing later attention and learning; it may promote self-efficacy and control, encouraging competence and performance; responsiveness may foster security, thereby influencing exploration and learning; it may instill motivation to acquire information and persist; and it may show the child that his or her actions are correct and important. 
Contingent responding is related to secure attachment and overall competence and happiness (Clarke-Stewart, 1973). Responsiveness has also been found to predict a number of cognitive and social competence measures. Responsiveness in infancy is related to representational competency, faster habituation to stimuli, and increased novelty preference; these results hold true when controlling for early competence and noncontingent stimulation (Bornstein \& Tamis-LeMonda, 1989). Maternal responsiveness as early as twelve to fourteen weeks predicted measures at four years of verbal, perceptual, and motor ability as well as a general index of cognitive performance (Lewis, 1993). Tamis-LeMonda and colleagues (1996) argue that interactive and responsive parents support more mature play and those who reinforce children's social efforts may make it easier to pair labels with their referents. They supported this claim by demonstrating that responsiveness to play at thirteen months of age predicted children's play sophistication (i.e., amount of symbolic play behaviors) for both solitary and joint-play scenarios. Responsiveness also predicts later language skills (Beckwith \& Rodning, 1996) and focused attention during play (Lawson, Parrinello, \& Ruff, 1992).

Responsiveness has been associated with social development as well (Beckwith \& Rodning, 1996). Maternal responsiveness at one year of age is negatively related to later disruptive behavior (i.e., two year aggression and three year externalizing behavior) in boys (Shaw, Keenan, \& Vondra, 1994), and parents' behavior can influence child compliance by being context-appropriate and responsive (Landry, Garner, Pirie, \& Swank, 1994). Parpal \& Maccoby (1985) demonstrated that only maternal responsiveness, not warmth and sensitivity, increased child compliance. 
Such findings as these are not artifacts of laboratory study. The home observations of Bornstein and Tamis-LeMonda (1989) indicate that responsiveness to infants' nondistress behaviors is associated with concurrent exploration and vocalization and predicts preschool cognitive competence. These researchers also replicated these findings cross-culturally. When Landry and colleagues (2001) compared the predictive power of the cognitive components of responsiveness (increased stimulation, decreased restrictiveness, maintaining the child's focus of attention) and the affective components (warm sensitivity) few differences were found, suggesting that both components reflect the overall nurturance and sensitive support associated with responsiveness.

Much of the research that investigates the link between responsiveness and child outcomes has focused on early interaction, particularly within the first year of life, but when the special importance of early responsiveness is examined, consistency across childhood is found to be more advantageous than early responsiveness in particular (Landry et al, 2001). For instance, mothers who were consistently high in their responsiveness had children who scored higher on measures of cognitive and social skills than children of mothers with consistently low responsiveness or high responsiveness only early in their children's lives. The results of this study indicate that there is no special importance for early responsiveness (although inconsistent responsiveness is better than none at all). Furthermore, because skills change across development, parents need to demonstrate consistent responsiveness throughout childhood to maintain a positive developmental trajectory. 


\section{Parent Response Strategy}

Another important characteristic of parental interaction is the type of behavior or strategy used. There is a wide range of types of parental behavior in the literature, including information-providing statements, praise or positive feedback, demonstrations, suggestions, questions, labels, and directive statements (Garner, Rennie, \& Miner, 1996; Stevens, Blake, Vitale, \& McDonald, 1998; Landry, MillerLoncar, \& Swank, 1998; Lawson, Parrinello, \& Ruff, 1992; Clarke-Stewart, 1973; Landry, Smith, Miller-Loncar, \& Swank, 1998; Landry, Garner, Pirie, \& Swank, 1994). Garner, Rennie, and Miner (1996) differentiated between structured (demonstrating, physically orientating the child, interfering) and nonstructured (showing or offering toy) strategies emphasizing the positive aspects of nonstructured interactions, which provide children with some autonomy over the interaction.

Many of these strategies have been shown to predict various child outcome measures. Labels and suggestions are positively associated with Bayley MDI scores and vocabulary (Stevens et al, 1998) and information-providing statements increase independent goal-directed play in typically developing infants (Landry, Miller-Loncar, \& Swank, 1998). Presenting or offering an object is positively related to focused exploration, whereas demonstrations, switching objects, and physical manipulations are negatively associated with focused exploration (Lawson, Parrilnello, \& Ruff, 1992), especially for infants with relatively low or moderate levels of attention during solitary play. In this study, casual looking (rather than focused attention) was associated with restrictiveness, intrusions, and demonstrations. Restrictiveness such as using "do" and "do not" commands to direct children's behavior is negatively related to infant activity 
and exploration when engaged in solitary play (Clarke-Stewart, 1973) and to slower increases over time in child responsiveness and initiating during social interactions (Landry, Smith, Miller-Loncar, \& Swank, 1998).

Response strategies may vary with individual differences in parents. For example, Garner, Rennie, and Miner (1996) found that adolescent mothers demonstrate and interfere more than their adult counterparts. Strategies may also vary with context. More suggested actions and fewer directives have been observed during social play than teaching exercises (Landry, Garner, Pirie, \& Swank, 1994). The authors of this study posit that parents may be able to increase child compliance by making strategies context appropriate. Response strategies may also vary as a function of child age. ClarkeStewart (1973) observed that verbalizations directed toward children shift from more social in nature to more directive in the second year. In another study, toddler age was inversely related to demonstrations and nonverbal responses, but positively related to showing or offering objects (Garner, Rennie, \& Miner, 1996). Lastly, gender differences may exist in the parents' selection of response strategies. For example, Stevens and colleagues (1998) observed higher proportions of labels for females and more comments and questions directed toward males in the first year and a half.

\section{Attention-Directing Strategy}

An important indicator of the appropriateness of response is whether the parent follows (maintains, extends) or interrupts (introduces, redirects) the child's current focus of attention. Parents can seemingly increase their infants' emotional responsiveness by being sensitive to their current attentional focus (Garner \& Landry, 
1994). Attention directing affects language development indirectly via play competence and social behaviors (Laasko, Poikkeus, Eklund, \& Lytinen, 1999). Similar to attention directing, Rocissano, Slade, and Lynch (1987) discuss synchronous (following) versus asynchronous (interrupting) parent and child behaviors. In their study, child compliance was related to mother's synchrony and children were more likely to respond to synchronous instructions from the mother. Furthermore, mother's flexibility (i.e., adapting to child's asynchrony) increased compliance. Attentiondirecting strategies may also vary with some individual differences in parents. For instance, Laasko and colleagues (1999) found that extending behavior was associated with mothers' education level. Garner, Rennie, and Miner (1996) observed that adolescent mothers used fewer introducing and more redirecting strategies than their adult counterparts.

Attention maintaining behaviors hold the child's current focus of attention, rather than redirecting it to another object or person. Maintaining is associated with many positive child outcomes, such as greater increases over time in child responsiveness and initiation of exchanges during both play and, in particular, daily activities (Landry et al, 1998). Conversely, parent behaviors that redirect their children's attention are negatively associated with cognitive competence (Garner \& Landry, 1994). According to the work of Landry and Chapieski (1989), infants are affected by how much parent attention-directing behavior taxes their attentional capacity. Maintaining reduces attentional demands because children do not have to break attention with one object and shift it to something else. For this reason, redirecting may limit an infant's ability to explore by taxing attentional capacity. 
Parents may also employ introducing behavior when the child has no immediately preceding focus of attention. Although this does not require a shift of attention from one object to another, Garner and Landry (1994) argue that it does require the child to shift from a passive state of attention to an active one. This can be particularly problematic if infants and young children use these pauses in activity as "down time", or an opportunity to take a break from interaction. In the work presented by Garner and Landry (1994), introducing behavior, as well as redirecting, was associated with low interest (i.e., emotional responsiveness) in 6-month-olds during joint play with their mothers. Introducing appears to be relatively rare; maintaining and redirecting were both used more often than introducing in the Garner, Rennie, and Miner (1996) study.

One final attention-directing strategy is extending. This is a type of maintaining behavior in which the parent elaborates upon the current play scheme. For instance, if a child is holding the receiver of a toy phone to his or her ear, the parent might extend by demonstrating how to dial a phone number on the keypad. Extending is simply a more complex form of maintaining, although some differences do appear to exist. According to the work of Laasko and colleagues (1999), extending is associated with play maturity (i.e., symbolic play behaviors) as well as socially coordinated play behaviors.

Extending also predicts later language comprehension in toddlers between one and three years, whereas maintaining predicts concurrent comprehension. Like introducing, extending appears to be relatively rare, with maintaining being observed more often than extending or redirecting (Laasko et al, 1999). 


\section{Parent Involvement}

A final way in which parents may enhance their children's development is through active involvement in their play. In Slade's (1987) study, toddlers exhibited substantially longer play episodes and more symbolic play when their mothers were physically involved and making suggestions than when they only commented on childinitiated verbal interactions. Notably, both types of interactions elicited longer and more mature play episodes than a complete lack of interaction. Alessandri (1992) also found an association between maternal involvement and qualitative level of play. Furthermore, active involvement in play seems to enhance subsequent social and language development (Parks \& Bradley, 1991)

\section{Television as Background Noise}

One way that background television could affect parent-child interaction is through interference via background noise. Although there is some evidence suggesting that performance on certain tasks is actually enhanced by ambient noise, background noise containing speech (as compared to white noise or noise produced by machines) can be detrimental to performance, particularly on complex cognitive tasks (Baker and Holding, 1993). Wachs (1986) suggests that a child's physical environment may mediate his or her social environment, rather than (or in addition to) the reverse. He also posits that not only too little stimulation, but also too much stimulation from the environment, may be detrimental to the development of infants. Wachs' research (1986) indicates that background noise in the home, of which television is a major contributor, negatively affects cognitive development independent of related factors, 
such as overall activity level in the home and overcrowding. In this study, background noise at six months predicted 24-month language ability measures and appeared to inhibit early attention development. Corapaci and Wachs (2000) found that background noise was negatively related to maternal verbal responsiveness. Wachs (1986) suggests that background noise may interfere with parent verbal stimulation, thereby reducing contingent response.

\section{Television, Distraction, and Distractibility}

Background television may affect parent-child interaction by distracting the parent or interfering with the parent's ability to respond by taxing his or her attentional capacity. Burns and Anderson (1993) observed attentional inertia in adults' televisionviewing behavior. Attentional inertia, the phenomenon that a bout of attention is more likely to continue the longer it has been sustained, provides resistance to distraction. In this case, the parent may become less able to shift attention away from the television in response to his or her child.

Abundant evidence exists to support the position that students' performance on homework assignments is substantially compromised in the presence of television (Pool, van der Voort, Beentjes, \& Koolstra, 2000; Pool, Koolstra, \& van der Voort, 2003a; 2003b). Similar to the results of Baker and Holding (1993), Armstrong and Greenberg (1990) found that background television can influence complex problemsolving tasks, although it did not appear to affect routine tasks, such as short-term memory and language processing. Importantly, this effect did depend on intentional allocation of attention, such that the television could be ignored if subjects were actively 
attempting to do so. These authors posit that background television may decrease performance on complex tasks by diverting processing capacity. To the degree to which interacting with a child is a complex activity requiring one's attention, it can be supposed that television may reduce the effectiveness or quality of that interaction.

\section{Overview of the Present Study}

The goal of this study was to investigate the impact of background television on parent-child interaction during toy play. A vast literature exists to emphasize the importance of parent interaction and responsiveness during the first several years of life. Previous studies have found a negative relationship between early television exposure and subsequent cognitive development. Although some findings suggest that noise in the home is negatively associated with parent responsiveness, this study is the first to address the potential impact of background television in particular on parent-child interaction. By comparing the quantity and quality of parent and child social behaviors with and without background television, this study is a first step in explaining how television may indirectly influence development via parent-child interaction. The extent to which background television has a negative impact on parent-child interaction, either by reducing the overall amount of interaction or by disproportionately decreasing certain positive types of behaviors, explains one way that early exposure to background television may negatively affect development.

In this study, very young children ( 24 and 36 months of age) and their parents played in a room for one hour. For one half of the hour, a television program selected by the parent played in the background. The television remained off for the other half- 
hour. The television programs available consisted of popular adult shows to which children were not expected to pay active attention, thus becoming background. The sessions were videotaped and subsequently coded for several parent and child social behaviors including responsiveness, attention-directing strategy, and involvement. Children's self-directed, object-oriented speech was also coded.

\section{Hypotheses}

\section{Overall Parent Interaction and Responsiveness}

Background television appears to interfere with complex task performance (Armstrong \& Greenberg, 1990; Baker \& Holding, 1993) and can elicit a resistance to distraction via attentional inertia (Burns \& Anderson, 1993). Background noise in the home, of which television is a substantial contributor, is associated with decreased parent responsiveness and stimulation in the home (Wachs, 1986). In light of these findings, less overall parent-child interaction in the presence of background television and reduced responsiveness to explicit requests on the part of the parent and the child are predicted. Because the television stimuli were programs for adults that parents were much more likely to understand (and consequently watch) it is also hypothesized that the impact of television would be stronger on parents than on children.

\section{Quality of Parent Interactions}

To the extent to which interacting with a child is complex, background television is expected to have a negative effect in light of prior research. In particular, disproportionate reductions in more elaborative and complex behaviors (e.g., 
information-providing statements, questions, suggested actions, extending behaviors, and active involvement) and behaviors that are parent-initiated rather than responsive are predicted.

\section{Child Behavior}

Child social behaviors are expected to decrease with television, but the prediction for self-directed speech is less clear. Assuming that parents watched the television at least some of the time that it was on, children would have spent more time in solitary play, which may lead one to predict an increase in self-directed, objectoriented speech with television. However, background television also appears to interfere with auditory processing, thus having a negative impact on self-directed speech (Evans et al, 2004a). As a result, it is difficult to predict whether television has a cumulative positive or negative effect on self-directed speech, or if the direct negative impact on self-directed speech and indirect positive effect via decreased parent interaction cancel each other out.

\section{Child Age and Sex}

There are no specific predictions regarding the impact of background television on the basis of age or sex. It is predicted that older children are more responsive to explicit parent requests and are more verbal, exhibiting more social and self-directed speech than the younger age group, in light of their more advanced verbal ability. There are no specific predictions with regard to parent-child interaction for the sex of the child. 


\section{Order of Conditions}

Because parents may become weary dealing with their children over the hourlong session, it is hypothesized that the negative impact of television on parent responsiveness and interaction will be stronger when the TV condition is second. That is, parents are expected to be more involved and interactive when the session first begins, regardless of condition, but as time passes it is predicted that television becomes a more powerful distracter. This effect is tested by including the order of conditions (TV first, TV second) as a between-subjects factor in each analysis. 


\section{CHAPTER 2}

\section{METHODS}

\section{$\underline{\text { Design }}$}

There were two conditions in this study: TV and No TV. In the TV condition, children played with their parents in the presence of a background television program for approximately 30 minutes. The No TV condition was a 30 -minute session of play without television in the background. The design was within-subjects and counterbalanced such that half of the participants played in the presence of background television for the first half-hour of the session while the other half played with television on in the background after a half-hour of play without television. This design also allowed between-subject comparisons between orders (e.g., the impact of television when it was presented in the first half-hour versus the second half-hour of the session).

\section{Participants}

Participants for this study were 17 children aged 24 months ( 9 males and 8 females) and 18 children aged 36 months ( 9 males and 9 females), each accompanied by one parent. All children participated in the study within one month of their second or third birthday. Two of the 35 parents in the study were fathers, the rest mothers. The fathers did not differ significantly from mothers on any of the dependent measures. All dyads in the study were Caucasian and residents of the Springfield, Massachusetts, metropolitan area. Information on socio-economic status was collected in the form of the highest level of education completed by each subject's mother and father. The 
highest degree obtained by either parent was a high school diploma for $20 \%$ of the sample, an undergraduate degree for $54 \%$, and a graduate degree for $26 \%$. Participant names and telephone numbers came from state birth records. Parents were each sent a letter describing the study and a few days later called to request participation. Children received a T-shirt as a small gift for participating and parents were compensated for parking expenses.

\section{Setting and Apparatus}

The study was run at the University of Massachusetts Child Study Center. This is a four-room suite located in an office building in Springfield, Massachusetts. Two rooms were used for this study: a playroom and an observation room.

Each child and his or her parent spent the entire hour-long session in a 4.27 by 3.81 meter playroom furnished with an armchair, a table with current magazines and newspapers, an open-shelved toy chest with age-appropriate toys, and a $48.26 \mathrm{~cm}$ television set on a stand. There was also a digital video camera hidden in a box beneath the television stand to record children's play when they were out of view of a second camera in the observation room. This latter camera, mounted on a tripod, was actively controlled by an experimenter through a one-way mirror. A microphone was placed in the observation room as well, which was connected to a digital video recorder in the observation room to record utterances by the parent and child.

The observation room was an adjacent room separated by a one-way mirror. Both cameras were connected to the digital video recording deck. The observer used a mixer to switch between camera views. The active camera in the observation room was 
the default camera, and the stationary camera in the playroom was used only when the child's back was turned toward the one-way mirror and the stationary camera provided a better view of the child's face and hands. There was also a video monitor in the observation room allowing the observer to see both camera views and switch between cameras to maintain the clearest and most useful angle.

A television set and video cassette player in the playroom was used to present the background television stimuli. The observer controlled this equipment from the observation room using remote controls. The experimenter also used a stopwatch to time the sessions.

\section{$\underline{\text { Stimuli }}$}

Parents in the study chose from a library of half-hour television shows. All of the stimuli were prerecorded and approximately 30 minutes in length with their natural commercials at the time if airing. These shows were popular programs targeting an adult audience at the time of the study ranging in type and not normally containing content that may be offensive to adults or objectionable for young children. Each individual episode was previewed by research assistants to ensure that no explicit offensive content was present. The 11 television shows available for the parents to choose from were Friends, Mad about You, Spin City, Frasier, The Cosby Show, Home Improvement, Everybody Loves Raymond (all popular situation comedies), Essence of Emeril (a cooking show), This Old House Classics (a home repair show), Jeopardy! (a game show), and A Makeover Story (a daytime reality show). 


\section{Toys}

The playroom was equipped with a variety of age-appropriatc toys (as designated by the manufacturer) with a consistent location at the beginning of each session. All toys were washable and chosen with safety as a primary coneern. The range of toys supported sensorimotor, constructive, and symbolic play. The standard toy set included: a baby doll, a wooden cradle, baby accessories (blanket, bottle, pacifier, plastic food jar, spoon, and brush), a jack-in-the-box, a teddy bear, a coloring book and crayons, a plastic toy broom, a plastic children's book, stacking cups, a shape sorter, a plastic bus with removable people, a plastic dish set and food, wooden puzzles, wooden building blocks, a toy phone, and a dump truck filled with interlocking blocks.

\section{Procedure}

When a parent and child first arrived at the Child Study Center, they were offered a snack and drink and then ushered into the play room where the child often began to acquaint him or herself with the toys. The experimenter started recording as soon as the parent and child entered the playroom so that all play was captured. The parent was first asked to sign an informed consent form and then select a tclevision program from a list of shows available. After any remaining questions were answered, the experimenter left the room.

The session began when the experimenter entered the observation room. For the TV-first order, the experimenter then played the stimulus tape. For the TV-second order, the experimenter set the stop-watch for 30 minutes of play without television. After 30 minutes, the experimenter used a remote control to either turn off the telcvision 
(in the TV-first order) or to turn on the television and begin the stimulus tape (in the TV-second order). In both the TV and No TV conditions, the child was free to play with all of the toys. Parents were encouraged to act as they normally would at home, playing with their child, reading the magazines and newspapers provided, or watching the television while it was on.

At the end of the session, the experimenter entered the room and debriefed the parent. The parent was given another consent form that he or she could choose to sign or not sign giving permission to show clips of the videotaped session for the purpose of presenting data from the study to professional audiences. The parent was also asked to complete a short questionnaire with items regarding the child's environment, televisionviewing behavior, and exposure to television at home. A copy of the parent questionnaire is provided in Appendix A.

\section{Videotape Coding}

Verbal interactions for both the parent and child were coded simultaneously in one pass through each tape. The level of parent involvement was coded in a second pass. A paper-and-pencil technique was employed. Each tape was divided into 10second intervals, beginning with the first second of the session, and behaviors were recorded by writing the corresponding letter in the appropriate cell. Verbal behaviors were coded for each interval if they occurred at least once within those ten seconds, regardless of how many instances there were in any given interval. Categories of parents' verbal behavior were response type, response strategy, attention-directing strategy, and responsiveness to explicit child requests. Child behaviors coded were 
behavior type and child responsiveness to explicit requests by the parent. Lastly, each 10-second interval received one of six possible codes for the degree of parent involvement characteristic of that interval. Although it was not possible to conceal the experimental manipulation, coders were blind to all specific hypotheses about the study. A sample coding sheet is provided in Appendix B. Following is a detailed description of the coding scheme.

\section{Parent Response Type}

Parent response type refers to whether or not the interaction was contingent and appropriate to the child's previous activity, whether or not it was in response to the child, and if so to what type of behavior it was in response to. The four behaviors coded in this category were response to verbal social behavior, response to nonverbal social behavior, unsolicited responses, and spontaneous utterances.

A "V" was coded when the parent answered a question asked by the child, repeated what the child said, engaged in reciprocal conversation, or otherwise responded to a social (rather than self-directed) verbal behavior from the child. Parent responses to nonverbal social behaviors $(\mathrm{N})$ were those in which the child was requesting the parent's attention or otherwise engaging the parent with nonverbal behavior, such as presenting a toy to the parent. Unsolicited parent behaviors (U) were recorded when the parent responded to the child's verbal or nonverbal self-directed behavior. That is, these behaviors were not responsive in that they were not requested by the child, but they were appropriate in relation to the child's concurrent behavior. Examples of unsolicited behavior include interrupting self-directed speech during object 
play or interfering to prevent the child from engaging in inappropriate behavior.

Finally, spontaneous behaviors (S) were those that were not in response to either the child's social or self-directed behavior. This behavior can be thought of as general verbal stimulation that is neither responsive to nor contingent on the child. For example, an "S" would have been coded if a child was playing with the puzzles on the floor and the parent commented on a magazine article that he or she was reading.

\section{Parent Response Strategy}

Response strategy addressed general acknowledgement of the child's behavior, whether or not parents provided information to their children, and whether the behavior was structured or unstructured. This category included labels, information-providing statements, demonstrations, questions or suggested actions, praise or positive acknowledgement of the child, and directive statements.

Labels (L) occurred when the parent provided a name for an object or part of an object that the child had not previously labeled in the session. Information-providing statements (I) were coded when the parent provided information about an object, such as physical characteristics, functional properties, or location, to the child. If the parent showed the child how to use an object or part of an object or did something for the child that he or she could have done independently, a demonstration (D) was coded.

Directive statements (i.e., "do" or "do not" commands) were coded as " $R$ ". The code "Q" signified questions or suggested actions. These included explicit questions directed toward the child or suggestive (rather than directive or demonstrative) behavior during play, such as handing or offering a toy or proposing what the child could, rather than 
should, do with an object. Finally, "P" was coded when the parent praised the child or otherwise positively acknowledged the child without adding information or dimension to play. There was also a code for "other" $(\mathrm{O})$ reserved for behaviors that did not easily fall into the above categories (e.g., the parent answering questions not related to play).

\section{Attention-Directing Strategy}

Attention-directing strategies were defined by the object of the parent's behavior in reference to the previous focus of the child's attention. Behaviors within this category included maintaining, extending, introducing, and redirecting.

Maintaining $(\mathrm{M})$ referred to any response to the child or spontaneous utterance that did not attempt to shift the child's focus of attention while encouraging concurrent play. Extending (E) was a particular type of maintaining behavior in which the parent added substantive information or a new dimension of play to the interaction. This behavior included demonstrating a new use for an object (e.g., dialing the telephone when the child was holding it to his or her ear), incorporating new objects into the play scheme (e.g., having the baby doll talk on the telephone), or providing information to help the child do something on his or her own (e.g., explaining why the stacking cups will not fit together and how to put them in the correct order). Introducing behaviors (I) were attempts to direct the child's attention to an object when the child was not currently focused on one. Lastly, an " $R$ " was coded for redirecting when the parent attempted to direct the child's attention to a different object than the child was currently focused on. An "X" was coded for parent utterances that did not attempt to direct the child's attention to an object (e.g., asking the child if he or she wanted a snack). 


\section{Parent Responsiveness}

Each explicit child request was coded as either responded to or not responded to appropriately and promptly by the parent. An " $R$ " was coded to indicate a child request that was appropriately responded to within three seconds. Child requests that were not responded to appropriately and promptly were coded as "N" for this category.

\section{Child Behavior Type}

The coding scheme for type of child behavior differentiated between verbal and nonverbal behaviors as well as social and self-directed utterances. The three types of child behaviors were verbal social behaviors, nonverbal requests, and self-directed, object-oriented speech. The code "V" was used for child utterances that were social in nature. An "N" was coded for nonverbal behaviors directed toward the parent. In particular, these were requests from the child such as presenting an object to the parent for help or handing an object to the parent to initiate a social exchange. Finally, selfdirected, object-oriented speech (S) was reserved for nonsocial utterances during toy play. Other utterances that were not clearly social in nature or object-oriented were coded as "O".

\section{Child Responsiveness}

Each explicit parent request (i.e., a question, suggested action, or directive) was coded as responded to or not responded to promptly by the child. An " $R$ " was coded if the child responded to the parent request within three seconds. Parent requests that were not responded to promptly were coded as "N". 


\section{Parent Involvement}

The involvement scale was used to describe the parent's focus of attention and engagement in the child's activity beyond verbal commentary. Because this coding scheme was designed to provide a more broad description of the parent's behavior, each ten-second interval was coded as one and only one level of involvement that best characterized the parent's behavior during that interval. In other words, brief comments that occurred only once in a given interval were not enough to characterize a parent as interacting in any way during that interval. The five levels of involvement were: not interacting, monitoring, non-object interaction, passive object play, and active object play.

Parents were coded as not interacting ("N") if their primary attentional focus was on something other than the child, such as the television or a magazine. An " $\mathrm{M}$ " was used to denote monitoring when parents silently observed the child's activity without interacting in any other way. Non-object interaction ("I") was coded for intervals in which the parent and child were interacting but the focus of their activity was not object play. Examples include discussing events outside of the room (e.g., visiting family members later that day), tying the child's shoe, or talking about the television program. Object play was designated as either passive ("P") or active ("A"). To be considered actively involved, parents had to be in close physical proximity to their children (e.g., sitting on the floor near them) and their children had to be the primary focus of their attention. For example, a parent who was sitting back in the chair holding a magazine or watching television and casually acknowledging the child's requests would be coded as passively involved. Conversely, a parent sitting on the floor 
next to his or her ehild while physieally eontributing to objeet play would be coded as actively involved. A sixth code, "X", was used to denote intervals that were not eodable. These were instanees in which the parent was off-sereen and not interacting with the ehild. An "X" signified that the parent was either not interacting or monitoring, but clearly not engaged in passive, active, or non-object play.

\section{Reliability}

As part of the training process researeh assistants coded two training tapes and eompared their data to that of an experieneed eoder, making correetions where appropriate to achieve acceptable agreement. Coders then completed a test tape and inter-observer reliability (IOR) was assessed as deseribed below. If an individual's IOR for the test tape reached an aceeptable eriterion, that observer began coding tapes. Twenty-five pereent of the data (i.c., eight tapes) were double-eoded to assess IOR. This was done by ealeulating intra-elass correlations for TV and No TV total frequencies for each behavior. Only extending behavior did not achieve aeceptablc levels of IOR with an average intra-elass correlation of .43. The differences were by and large because coders disagreed on what was extending behavior versus nonelaborative maintaining. As a result, maintaining and extending behaviors werc combined to form one measure of behaviors that followed the child's focus of attention. The intra-class correlation coeffieicnt for this combined variable was .93. Intra-class correlations for four of the variables (spontaneous eomments, information-providing statements, and mother and child responsiveness) wcre between .70 and .79. All other correlations were above .80 . 


\section{CHAPTER 3}

\section{RESULTS}

Some of the parent and child behaviors were relatively infrequent (i.e., occurred in less than five percent of the total intervals) and therefore were combined with other behaviors that shared similar properties. Furthermore, additional measures were formed from the involvement scale. These combinations are described in further detail within each category below. See Table 1 for descriptive statistics for all original dependent measures and Table 2 for the combined dependent measures used in the final analyses. All categories of behaviors were subjected to analyses of variance with condition (TV, No TV) and behavior type (where appropriate) as repeated measures. Because there was no correction for multiple tests thereby increasing the chance of a Type II error, a significance level of .01 was used.

\section{Overall Parent Verbal Interaction}

Total parent verbal interactivity was measured by summing the intervals with any verbal interaction and dividing by the total number of intervals in each session. These data were then subjected to a 2(age of child: 24,36 months) x 2(sex of child: male, female) x 2(test order: TV first, TV second) analysis of variance with condition (TV, No TV) as a repeated measure. This analysis revealed a negative impact of background television on overall parent verbal interaction, $F(1,27)=18.87, p<.01$ $(\mathrm{MSE}=.25)$. Parents spent $72 \%$ of the No TV condition verbally interacting with their children, compared to only $60 \%$ of the session when the television was on. 


\begin{tabular}{|c|c|c|c|c|}
\hline Behavior & Mean & Std. Dev. & Min. & Max. \\
\hline \multicolumn{5}{|l|}{ Parent Response Type } \\
\hline Response to verbal & .403 & .139 & .128 & .726 \\
\hline Response to nonverbal & .486 & .395 & .000 & .156 \\
\hline Unsolicited & .247 & .140 & .335 & .637 \\
\hline Spontaneous & .124 & .911 & .000 & .385 \\
\hline \multicolumn{5}{|l|}{ Parent Response Strategy } \\
\hline Label & .342 & .265 & .000 & .112 \\
\hline Information-providing & .129 & .092 & .011 & .489 \\
\hline Demonstration & .022 & .022 & .000 & .106 \\
\hline Question/Suggestion & .327 & .141 & .099 & .751 \\
\hline Directive & .114 & .083 & .006 & .460 \\
\hline \multicolumn{5}{|l|}{ Attention-directing Strategy } \\
\hline Maintaining & .474 & .171 & .139 & .823 \\
\hline Extending & .038 & .056 & .000 & .242 \\
\hline Introducing & .021 & .028 & .000 & .174 \\
\hline Redirecting & .069 & .059 & .000 & .275 \\
\hline \multicolumn{5}{|l|}{ Level of Involvement } \\
\hline Not Interacting & .198 & .162 & .000 & .705 \\
\hline Monitoring & .145 & .120 & .000 & .526 \\
\hline Non-object Play & .116 & .100 & .000 & .677 \\
\hline Passive Object Play & .113 & .072 & .000 & .275 \\
\hline Active Object Play & .314 & .215 & .022 & .989 \\
\hline \multicolumn{5}{|l|}{ Child Behavior Type } \\
\hline Child Verbal & .540 & .147 & .211 & .839 \\
\hline Child Nonverbal & .049 & .045 & .000 & .197 \\
\hline Self-directed & .179 & .127 & .000 & .546 \\
\hline \multicolumn{5}{|l|}{ Responsiveness } \\
\hline Parent responsiveness & .835 & .168 & .100 & 1.000 \\
\hline Child responsiveness & .632 & .139 & .359 & .935 \\
\hline
\end{tabular}

Table 1. Descriptive statistics for the average proportion of intervals containing each original target behavior and probability of responding for parents and children.

Figure 1 is a scatter plot of parents' verbal interactions with television regressed on baseline (i.e., No TV) interactions. The fitted line has an intercept of .15 and a slope of $.63, t(27)=4.37, p<.01(\mathrm{SE}=.144)$. Points that fall within the shaded area represent parents who interacted less with the television on. Similarly, points that fall in 
the clear space indicate more interaction with television, and points that fall directly on the line represent approximately the same number of interactions in both conditions. A vast majority of the data points fall within the shaded area, $Z=-3.93, p<.01$.

\begin{tabular}{lcccc}
\hline Behavior & Mean & Std. Dev. & Min. & Max. \\
\hline Parent Total Verbal Interactions & .660 & .175 & .282 & .983 \\
Parent Response Type & & & & \\
$\quad$ Responsive & .437 & .143 & .133 & .823 \\
$\quad$ Unsolicited & .247 & .140 & .335 & .637 \\
$\quad .124$ & .911 & .000 & .385 \\
$\quad$ Spontaneous & & & & \\
Parent Response Strategy & .156 & .095 & .016 & .516 \\
$\quad$ Informative & .327 & .141 & .099 & .751 \\
$\quad$ Suggestive & .131 & .087 & .006 & .506 \\
$\quad$ Restrictive & & & & \\
Attention-directing Strategy & .495 & .172 & .139 & .824 \\
$\quad$ Following & .089 & .070 & .006 & .324 \\
$\quad$ Interrupting & & & & \\
Level of Involvement & .543 & .192 & .193 & 1.000 \\
$\quad$ Total Time Interacting & .427 & .192 & .083 & .989 \\
$\quad$ Total Time in Object Play & .669 & .231 & .133 & 1.000 \\
$\quad$ Relative Active Object Play & & & & \\
Child Behavior Type & .568 & .140 & .232 & .839 \\
$\quad$ Child Social & .179 & .127 & .000 & .546 \\
$\quad$ Self-directed &
\end{tabular}

Table 2. Proportion of intervals containing each of the final combined dependent measures, percent of object play that was active, and probability of responding for both parent and child.

It is important to note that the slope of the line is less than one. In other words, the distance between the fitted line and unity (i.e., where $\mathrm{X}=\mathrm{Y}$ ) increases with baseline interaction, suggesting that the impact of television is proportional to baseline interactivity and therefore stronger for more generally interactive parents. Although this would be expected in light of regression to the mean, there is other evidence in support of this finding. Baseline interaction is significantly correlated with the absolute 
change with television and marginally correlated with the proportional change with television, $r(35)=.41, p=.01$, and $r(35)=.35, p=.04$, respectively. When the absolute and proportional changes in the number of intervals containing any verbal interaction are plotted against baseline interaction, the highest points consistently fall on the upper end of the $\mathrm{X}$-axis. Together, these findings suggest that the impact of background television on verbal interactions is proportional to baseline frequency, although it is not possible with the present design to rule out regression to the mean entirely as an explanation.

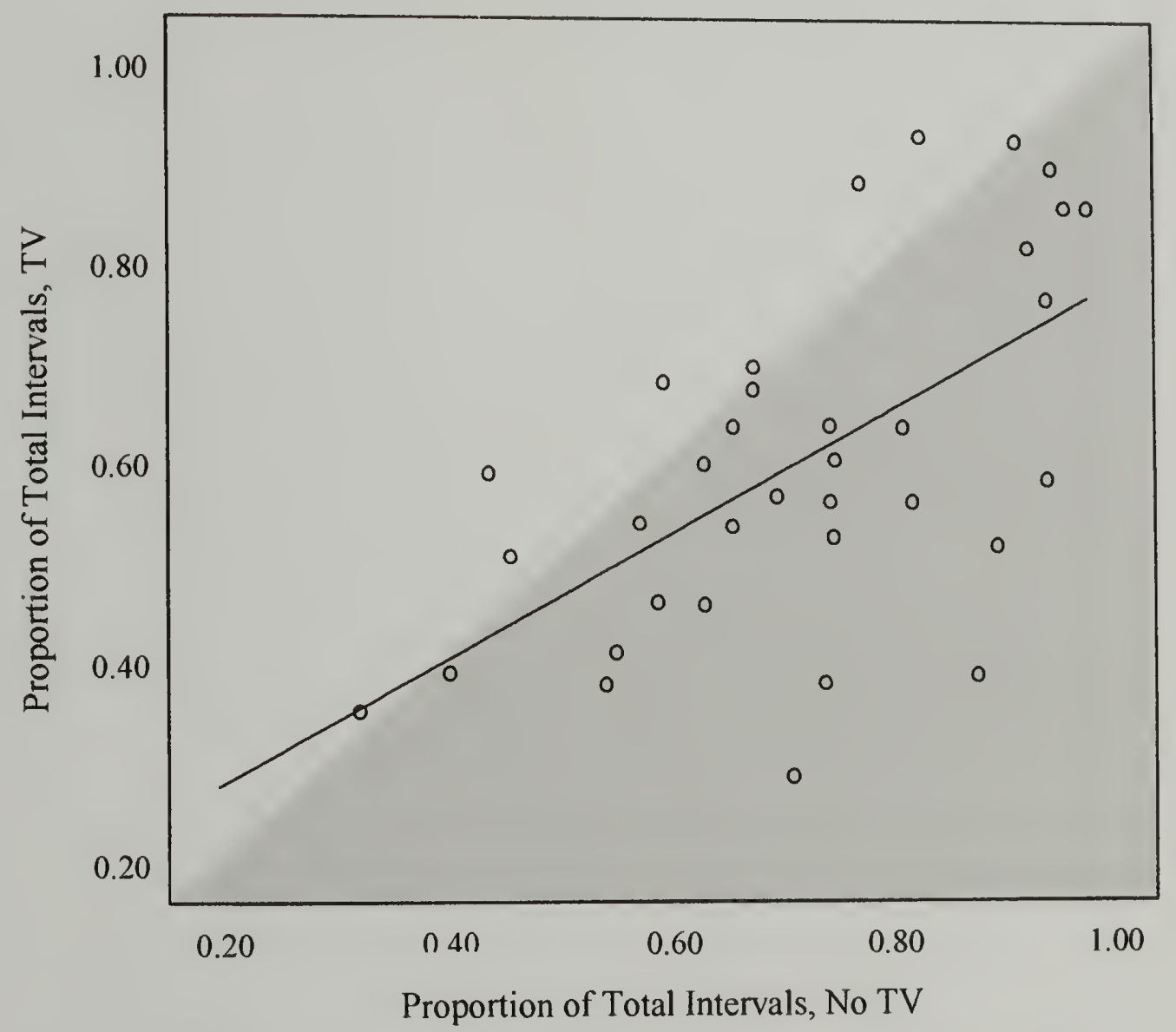

Figure 1. Proportion of intervals containing any parent verbal interaction with TV regressed on interactions without TV. Data points in the shaded area represent parents who interacted less with the TV on. 


\section{Parent and Child Responsiveness}

A 2(age of child) $\times 2$ (sex of child) $\times 2$ (test order) ANOVA was conducted on the parent and child responsiveness measures simultaneously. Condition (TV, No TV) and individual (parent, child) were repeated measures. The dependent measure was the proportion of total requests made by the other individual that received responses. There was a significant main effect of individual such that parents were more responsive to requests than were children, $F(1,27)=57.82, p<.01(\mathrm{MSE}=1.45)$. On average, parents responded to $83 \%$ of children's explicit requests whereas children, on average, responded to only $63 \%$ of questions and directives by the parent. Because there were significant condition by individual interactions, additional $2($ age $) \times 2$ (sex of child) $\mathrm{x}$ 2(test order) repeated measures ANOVAs were conducted on the parents' and children's responsiveness separately. Parents were more likely to respond to the requests of 36 -month-olds $(89 \%)$ than 24 -month-olds $(78 \%), F(1,27)=7.67, p=.01$ $(\mathrm{MSE}=.23)$. The older children, in turn, were more likely to respond to parents' requests $(56 \%$ versus $70 \%), F(1,27)=10.98, p<.01(\mathrm{MSE}=.30)$. For parents, but not for children, there was a marginally significant main effect of television, $F(1,27)=$ $6.48, p=.02(\mathrm{MSE}=.11)$. Parents responded to only $79 \%$ of child requests in the presence of background television compared to the No TV baseline of $87 \%$.

\section{Parent Response Type}

Because responses to nonverbal behaviors were relatively infrequent, they were combined with responses to verbal behaviors to create one measure of parents' responsive behavior. Dependent measures were then the proportion of total intervals 
per condition that contained responsive, unsolicited, and spontaneous parent behaviors.

See Table 3 for descriptive statistics with and without background television for all behaviors in this category. Table 4 presents these same data as a function of age group.

\begin{tabular}{lccc}
\hline & No TV & TV & \% Change \\
\hline Responsive & $.485(.14)$ & $.389(.15)$ & -19.79 \\
Unsolicited & $.283(.16)$ & $.211(.12)$ & -25.44 \\
Spontaneous & $.135(.10)$ & $.112(.08)$ & -17.03 \\
\hline
\end{tabular}

Table 3. Mean proportion of intervals containing each response type with standard errors in the No TV and TV conditions and percent change with television.

\begin{tabular}{|c|c|c|c|c|c|c|}
\hline & \multicolumn{3}{|c|}{24 Months } & \multicolumn{3}{|c|}{36 Months } \\
\hline & No TV & TV & Change & No TV & TV & Change \\
\hline Responsive & $.484(.14)$ & $.347(.16)$ & -28.31 & $.486(.14)$ & $.428(.13)$ & -11.93 \\
\hline Unsolicited & $.351(.16)$ & $.245(.10)$ & -30.20 & $.219(.14)$ & $.179(.13)$ & -18.26 \\
\hline Spontan. & $.169(.11)$ & $.128(.08)$ & -24.26 & $.104(.09)$ & $.097(.07)$ & -6.73 \\
\hline Total & $.338(.03)$ & $.243(.02)$ & -28.11 & $.271(.02)$ & $.236(.02)$ & -12.92 \\
\hline
\end{tabular}

Table 4. Mean proportion of intervals containing each response type with standard errors for 24- and 36-month-olds in the No TV and TV conditions and percent change with television.

The initial analysis was a 2(age) $\mathrm{x} 2$ (sex) $\mathrm{x} 2$ (order) ANOVA with condition (TV, No TV) and type (responsive, unsolicited, spontaneous) as repeated measures. As would be expected, there was a significant main effect of television on total interactions, $F(2,54)=24.61, p<.01(\mathrm{MSE}=.22)$. There was also a significant main effect of type such that responsive behaviors were the most common, followed by unsolicited behaviors, and lastly spontaneous verbalizations, $F(2,54)=110.78, p<.01$ $(\mathrm{MSE}=1.93)$. This was qualified by a type by age interaction, $F(2,54)=6.25, p<.01$ $(\mathrm{MSE}=.11)$. Unsolicited behaviors in particular were more common among parents of 
24-month-olds than those with older children. There was a marginally significant interaction between condition and age such that the overall effect of television was larger for the younger age group, $F(2,54)=5.35, p=.03(\mathrm{MSE}=.05)$. Lastly, there was a significant interaction between condition and type, $F(2,54)=4.59, p=.01(\mathrm{MSE}$ $=.03)$. Similar to findings on total verbal interactions, the negative impact of background television was proportional to baseline frequency (see Figure 2).

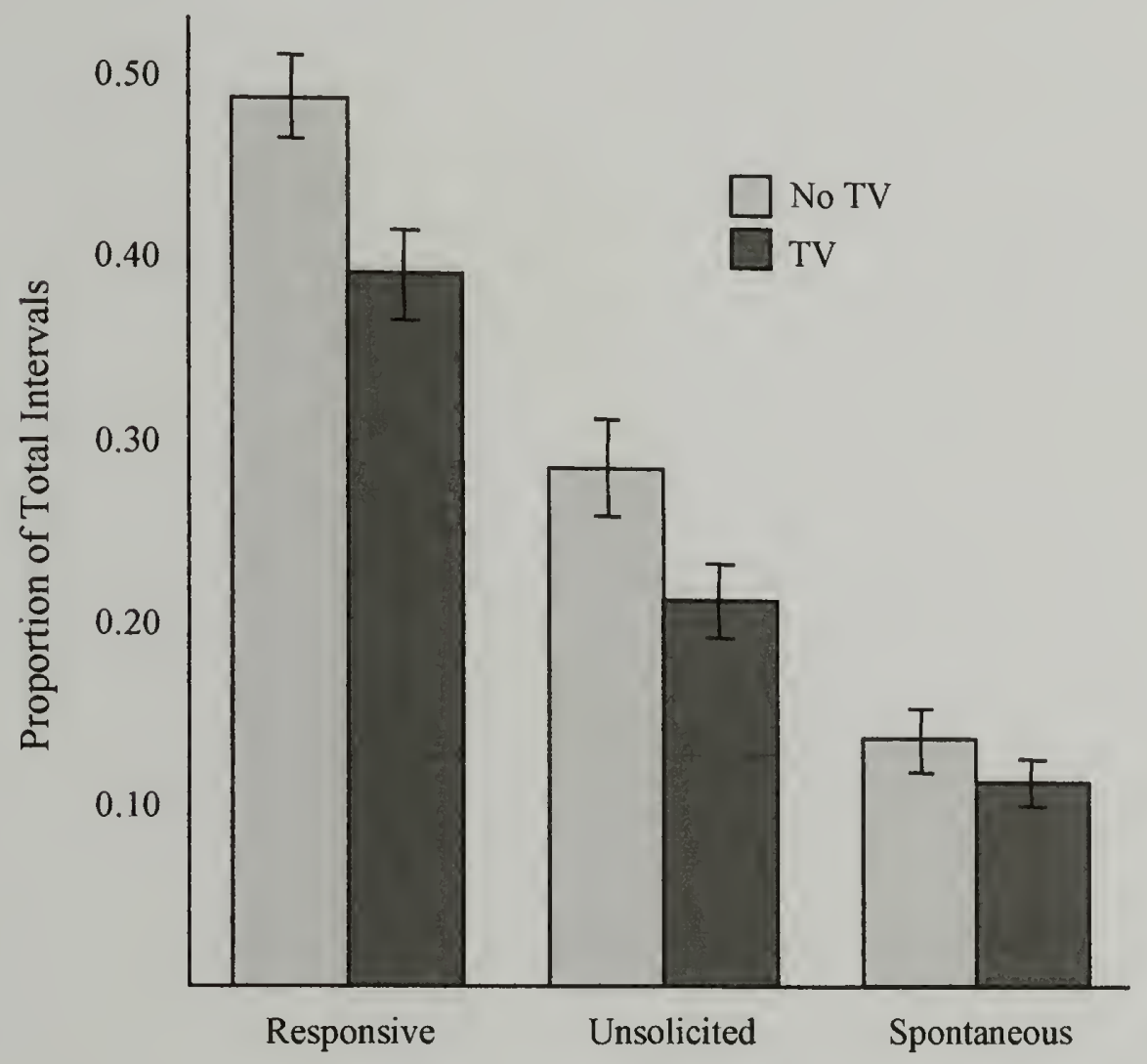

Figure 2. Proportion of intervals containing each response type in the No TV and TV conditions. Bars represent $+/$ - one standard error.

Because the effect of television differed depending on the type of behavior, separate 2(age) $\times 2$ (sex) $\times 2$ (order) repeated measures ANOVAs were run on each of the three behaviors in this category. There was a significant negative effect of television on 
both responsive and unsolicited behaviors, $F(1,27)=17.66, p<.01(\mathrm{MSE}=.17)$, and $F(1,27)=11.99, p<.01(\mathrm{MSE}=.09)$, respectively. The main effect of television on spontaneous behaviors was not significant. The only between-subjects difference was that there were more unsolicited behaviors directed toward 24-month-olds in general, $F(1,27)=7.14, p=.01(\mathrm{MSE}=.19)$. Although analyses based on the absolute frequencies of behaviors indicated that the effect of television was largest for the most common behaviors, different results are found with the degree of change relative to baseline frequency. The most dramatic proportional decrease was found for unsolicited behaviors, which decreased by $25 \%$. Response behaviors decreased by $20 \%$ with television and spontaneous verbalizations dropped by only $17 \%$.

\section{Parent Response Strategy}

The behaviors of particular interest in this category were labels, informationproviding statements, questions or suggested actions, demonstrations, and directives. Because the two miscellaneous categories ("positive acknowledgement" and "other") were not of any theoretical interest on their own, they were not subjected to individual analyses. They were, however, included in calculating the overall measure of verbal interaction and counted as responses to child requests where appropriate. Both labeling and demonstrating were relatively infrequent behaviors, occurring in less than five percent of the intervals, and often overlapped with other behaviors within the category. Therefore, labeling was combined with its more general counterpart, informationproviding, to create an overall measure of informative parent behavior. Demonstrations were considered closed-ended, structured behaviors (as compared to suggested actions) 
and therefore combined with directives to create a general measure of restrictive parent behavior. In some cases, demonstrations could be considered information-providing (e.g., showing the child how to perform a particular task). However, it was often the case that if a parent demonstrated a behavior with the intent of showing the child how to perform the task, an information-providing statement was coded for the utterance (e.g., "You turn the crank to make the clown pop out of the box.") while the demonstration was coded for the act of the parent taking the toy from the child to manipulate it him or herself. All analyses presented here are based on the combined restrictive variable; however, all analyses were rerun on directives alone with identical results. The final dependent measures for this category were the proportion of total intervals in each condition that contained informative, suggestive, and restrictive behaviors. See Table 5 for means and standard deviations with and without background television for these three behaviors.

The initial analysis was a 2(age) $\times 2$ (sex) $\times 2$ (order) repeated measures ANOVA with condition and type as within-subjects factors. As would be expected in light of previous results, there was a significant negative impact of television on overall interactions, $F(1,27)=22.25, p<.01(\mathrm{MSE}=.15)$. Questions and suggested actions were approximately twice as frequent as informative statements and directives, $F(2,54)$ $=61.88, p<.01(\mathrm{MSE}=.91)$.

\begin{tabular}{lccc}
\hline & No TV & TV & \% Change \\
\hline Informative & $.181(.10)$ & $.131(.09)$ & -27.62 \\
Suggestive & $.362(.14)$ & $.293(.14)$ & -19.06 \\
Restrictive & $.151(.11)$ & $.110(.06)$ & -27.15 \\
\hline
\end{tabular}

Table 5. Mean proportion of intervals containing each response strategy with standard errors for the No TV and TV conditions and percent change with television. 


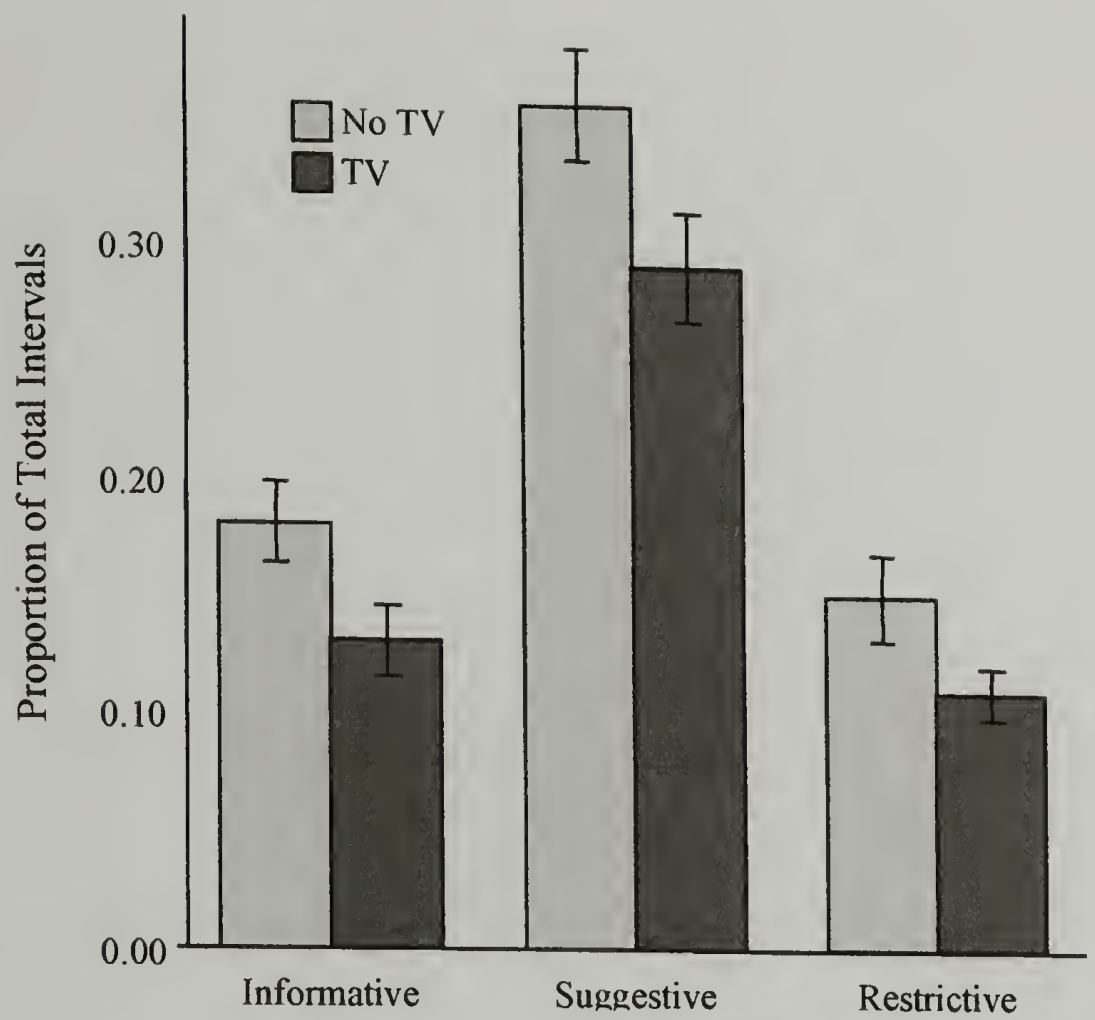

Figure 3. Proportion of intervals containing each response strategy in the No TV and TV conditions. Bars represent $+/$ - one standard error.

Because there were several significant interactions between condition, behavior type, and age, separate repeated measures ANOVAs were conducted on the three dependent measures. There was a significant negative effect of television on both informative and suggestive behavior, $F(1,27)=19.41, p<.01(\mathrm{MSE}=.04)$, and $F(1$, $27)=18.15, p<.01(\mathrm{MSE}=.09)$, respectively. The main effect of television on restrictive behavior was only marginally significant, $F(1,27)=6.65, p=.02(\mathrm{MSE}=$ .03 ; see Figure 3). Once again, however, different results were found when using the change with television relative to baseline frequencies. Informative and restrictive behaviors decreased by $28 \%$ and $27 \%$, respectively, whereas suggestive behaviors only decreased by $19 \%$. Importantly, the effect of television on suggestive behaviors was 
qualified by a significant condition by order interaction such that the effect of television was stronger on those dyads who had the TV condition in the second half-hour, $F(1,24)$ $=6.96, p=.01(\mathrm{MSE}=.03$; see Table 6$)$. The reduction in suggestive behavior was only $8 \%$ below baseline when the TV condition was first, but $29 \%$ below baseline when the TV condition followed 30 minutes of play without television. The only other between-subjects main effect was found for directives, which were nearly twice as common among parents of 24 -month-olds overall $(17 \%$ versus $9 \%), F(1,27)=9.40, p=$ $.01(\mathrm{MSE}=.10)$.

\begin{tabular}{lccc}
\hline & No TV & TV & \% Change \\
\hline TV First & $.330(.03)$ & $.303(.03)$ & -8.18 \\
TV Second & $.399(.03)$ & $.284(.03)$ & -28.82 \\
\hline
\end{tabular}

Table 6. Mean proportion of intervals containing suggestive behaviors in the No TV and TV conditions by test order and percent change with television.

\section{Attention-Directing Strategy}

As aforementioned, extending behavior did not achieve acceptable levels of inter-observer agreement and was therefore combined with its more general counterpart, maintaining. Together these behaviors were considered attention-following interactions. Furthermore, introducing behavior was relatively infrequent. Because introducing can be considered a form of redirecting behavior and is not often distinguished from redirecting in the parent-child interaction literature, the two were combined in the present study to create one overall measure of interrupting behavior. The miscellaneous behavior ("no attention-directing") was included in the calculation of the overall measure of verbal interaction but was not subjected to further individual analysis. The two dependent measures for this category, therefore, were the proportion 
of total intervals in each session that contained attention-following and interrupting behaviors. See Table 7 for means and standard deviations for these behaviors with and without television; Table 8 presents this data as a function of age group.

\begin{tabular}{lccc}
\hline & No TV & TV & \% Change \\
\hline Following & $.549(.16)$ & $.441(.18)$ & -19.67 \\
Interrupting & $.109(.08)$ & $.068(.06)$ & -37.61 \\
\hline
\end{tabular}

Table 7. Mean proportion of intervals containing each attention-directing strategy with standard errors in the No TV and TV conditions and percent change with television.

A 2 (age) $\times 2$ (sex) $\times 2$ (order) ANOVA with condition and type (following, interrupting) as repeated measures was performed. Again, there was a negative effect of television on overall interactions, $F(1,27)=32.32, p<.01(\mathrm{MSE}=.19)$. Attentionfollowing behaviors were substantially more frequent than interrupting behaviors, $F(1$, $27)=260.99, p<.01(\mathrm{MSE}=5.69)$, and the impact of television on absolute frequencies was stronger for attention-following, $F(1,27)=10.08, p=.04(\mathrm{MSE}=.04$; see Figure 4). As before, the overall effect of television was stronger for 24-montholds, $F(1,27)=7.39, p=.01(\mathrm{MSE}=.04)$.

\begin{tabular}{|c|c|c|c|c|c|c|}
\hline & \multicolumn{3}{|c|}{24 Months } & \multicolumn{3}{|c|}{36 Months } \\
\hline & No TV & TV & Change & No TV & TV & Change \\
\hline Follow & $.553(.04)$ & $.395(.04)$ & -28.57 & $.548(.04)$ & $.492(.04)$ & -10.22 \\
\hline Interrupt & $.151(.01)$ & $.090(.01)$ & -40.40 & $.072(.02)$ & $.051(.01)$ & -29.17 \\
\hline Total & $.352(.03)$ & $.242(.03)$ & -31.25 & $.310(.03)$ & $.271(.02)$ & -12.58 \\
\hline
\end{tabular}

Table 8. Mean proportion of intervals for 24- and 36-month-olds containing each attention-directing behavior with standard errors in the No TV and TV conditions and percent change with television. 
Separate 2(age) $\times 2$ (sex) $\times 2$ (order) repeated measures ANOVAs revealed significant main effects of television for both maintaining and redirecting behavior, $F(1$, $27)=23.59, p<.01(\mathrm{MSE}=.20)$, and $F(1,27)=24.51, p<.01(\mathrm{MSE}=.03)$, respectively. Again, although changes in absolute frequencies suggest that the impact of television was greater for the more common behavior (i.e., following), television had a more dramatic proportional effect on interrupting behaviors, which decreased by $38 \%$, than on following, which decreased by only $20 \%$. A significant age difference was also found such that interrupting behavior was more common among parents of 24-montholds overall, $F(1,27)=7.66, p=.01(\mathrm{MSE}=.06)$.

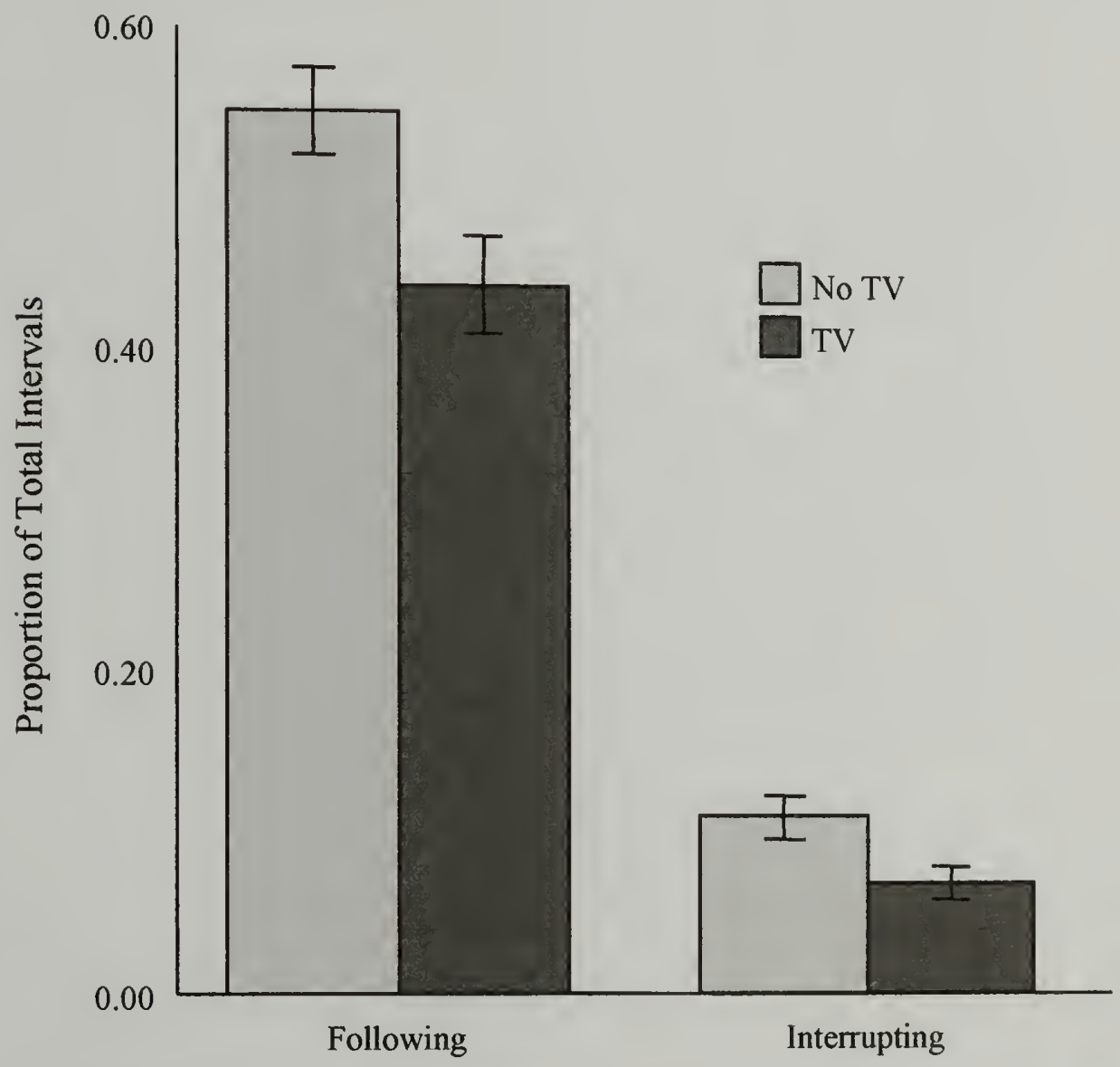

Figure 4. Proportion of intervals containing each attention-directing strategy in the No TV and TV conditions. Bars represent $+/$ - one standard error. 


\section{Child Behaviors}

The three child behaviors of interest were verbal interactions, nonverbal requests, and self-directed speech. The "other" category was a placeholder for miscellaneous behaviors not considered social in nature or object-oriented and thus not subjected to individual analysis. As with parent response type, verbal and nonverbal behaviors were combined to produce one measure of all social behaviors for children. The dependent variables, therefore, were the proportion of total intervals in each session that contained social behaviors and self-directed speech. See Table 9 for means and standard deviations for these behaviors with and without background television.

The data were subjected to a 2(age) $\mathrm{x} 2$ (sex) $\mathrm{x} 2$ (order) ANOVA with condition and type (social, self-directed) as repeated measures. Social behaviors were substantially more common than self-directed speech, $F(1,27)=165.17, p<.01$ (MSE $=5.38)$. There was also a significant interaction between condition and type, $F(1,27)=$ $16.75, p<.01(\mathrm{MSE}=.22)$. Social behaviors decreased in the presence of background television from $63 \%$ of the total intervals to $51 \%$, whereas self-directed speech increased from $16 \%$ to $20 \%$ (see Figure 5 ).

\begin{tabular}{lccc}
\hline & No TV & TV & \% Change \\
\hline Social behaviors & $.627(.13)$ & $.509(.15)$ & -18.82 \\
Self-directed speech & $.160(.12)$ & $.199(.13)$ & 24.38 \\
\hline
\end{tabular}

Table 9. Mean proportion of intervals containing each child behavior type with standard errors in the No TV and TV conditions and percent change with television.

Because it was predicted that background television may have an indirect negative effect on children's social interactions and an indirect positive effect on selfdirected speech by reducing overall parent interaction, the analysis was rerun with 
parents' total verbal interactions as a covariate. When controlling for parents' verbal interactivity, television did not have a significant effect on either social or self-directed speech. In separate repeated measures ANOVAs, only parent total interactions significantly predicted child social behaviors (positively) and self-directed speech (negatively), $F(1,26)=21.00, p<.01(\mathrm{MSE}=.33)$, and $F(1,26)=10.38, p=.03(\mathrm{MSE}$ $=.21$ ), respectively. Furthermore, when controlling for parent verbal interactions there was a significant main effect of age on social (but not self-directed) behavior such that older children were more talkative, $F(1,26)=8.96, p=.01(\mathrm{MSE}=.14)$.

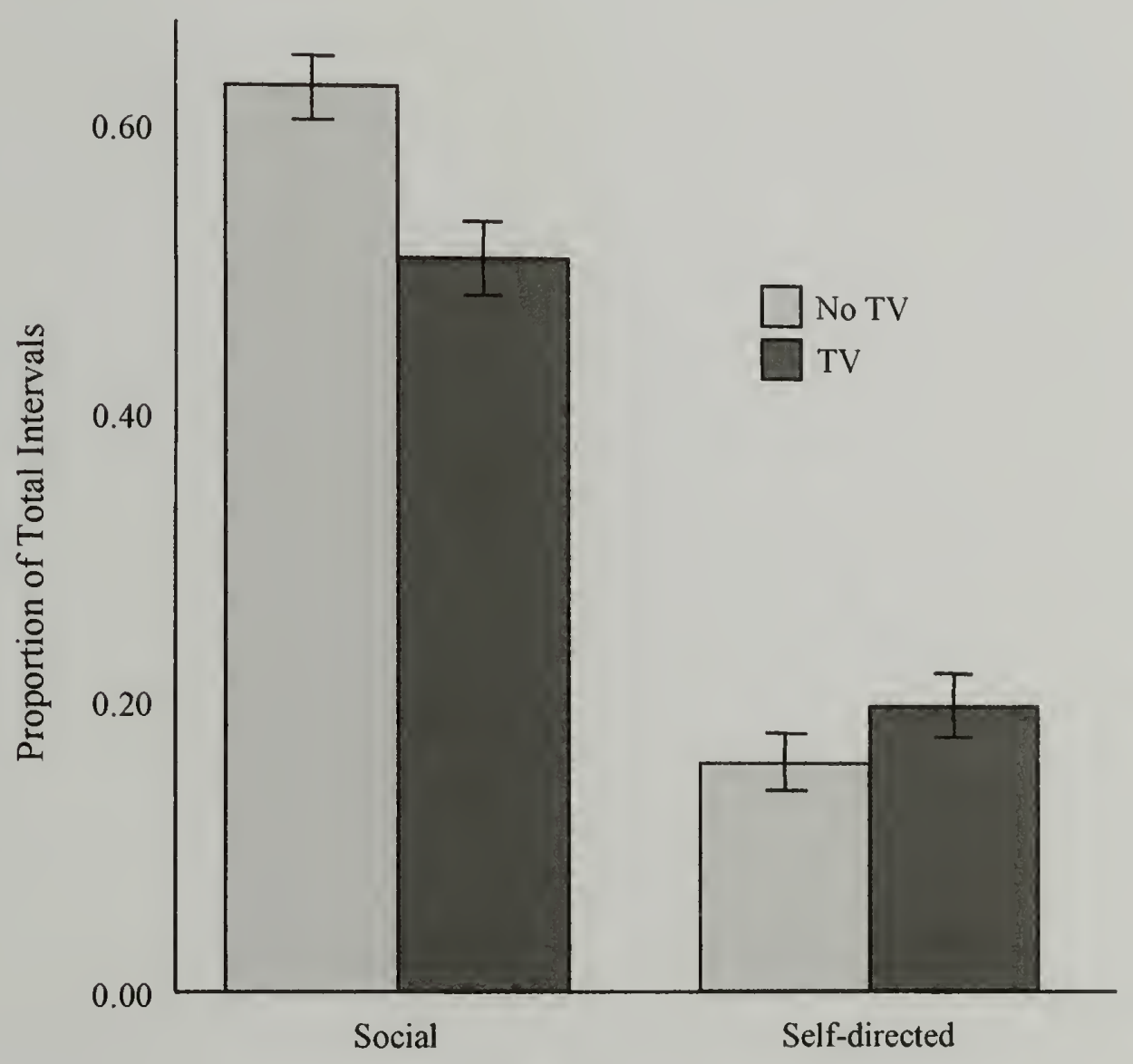

Figure 5. Proportion of intervals containing child social behavior and self-directed speech in the No TV and TV conditions. Bars represent $+/$ - one standard error. 


\section{Parent Involvement}

Separate 2 (age) $\times 2$ (sex) $\times 2$ (order) ANOVAs with condition as a repeated measure were conducted on the five levels of involvement, plus three combined measures (total time interacting, time spent in toy play, and relative active play).

Analyses on non-object play, passive object play, and active object play were based on the proportion of total intervals coded as each of these behaviors. Because "monitoring" and "not interacting" could not be coded when the parent was off-screen, these dependent measures were the proportion of total intervals minus those not codable that contained each of these two target behaviors. Fourteen percent of the No TV intervals and $21 \%$ of the intervals during the TV condition were not codable.

\begin{tabular}{llcc}
\hline & No TV & TV & \% Change \\
\hline Not interacting & $.142(.14)$ & $.253(.18)$ & 78.17 \\
Monitoring & $.157(.14)$ & $.134(.10)$ & -14.65 \\
Non-object play & $.134(.13)$ & $.098(.07)$ & -26.87 \\
Passive object play & $.106(.08)$ & $.120(.07)$ & 13.21 \\
Active object play & $.365(.23)$ & $.264(.21)$ & -27.67 \\
Total time interacting & $.605(.20)$ & $.482(.19)$ & -20.33 \\
Total time in object play & $.471(19)$ & $.384(.19)$ & -18.47 \\
Reiative active object piay & $.727(.04)$ & $.617(.04)$ & -15.13 \\
\hline
\end{tabular}

Table 10. Mean proportion of time spent at each involvement level and proportion of object play spent actively involved with standard errors for the No TV and TV conditions with percent change.

\begin{tabular}{lccc}
\hline & No TV & TV & \% Change \\
\hline TV First & $.308(.06)$ & $.285(.05)$ & -7.47 \\
TV Second & $.416(.06)$ & $.243(.05)$ & -41.57 \\
\hline
\end{tabular}

Table 11. Mean proportion of time spent actively involved in object play in the No TV and TV conditions by test order and percent change with television. 


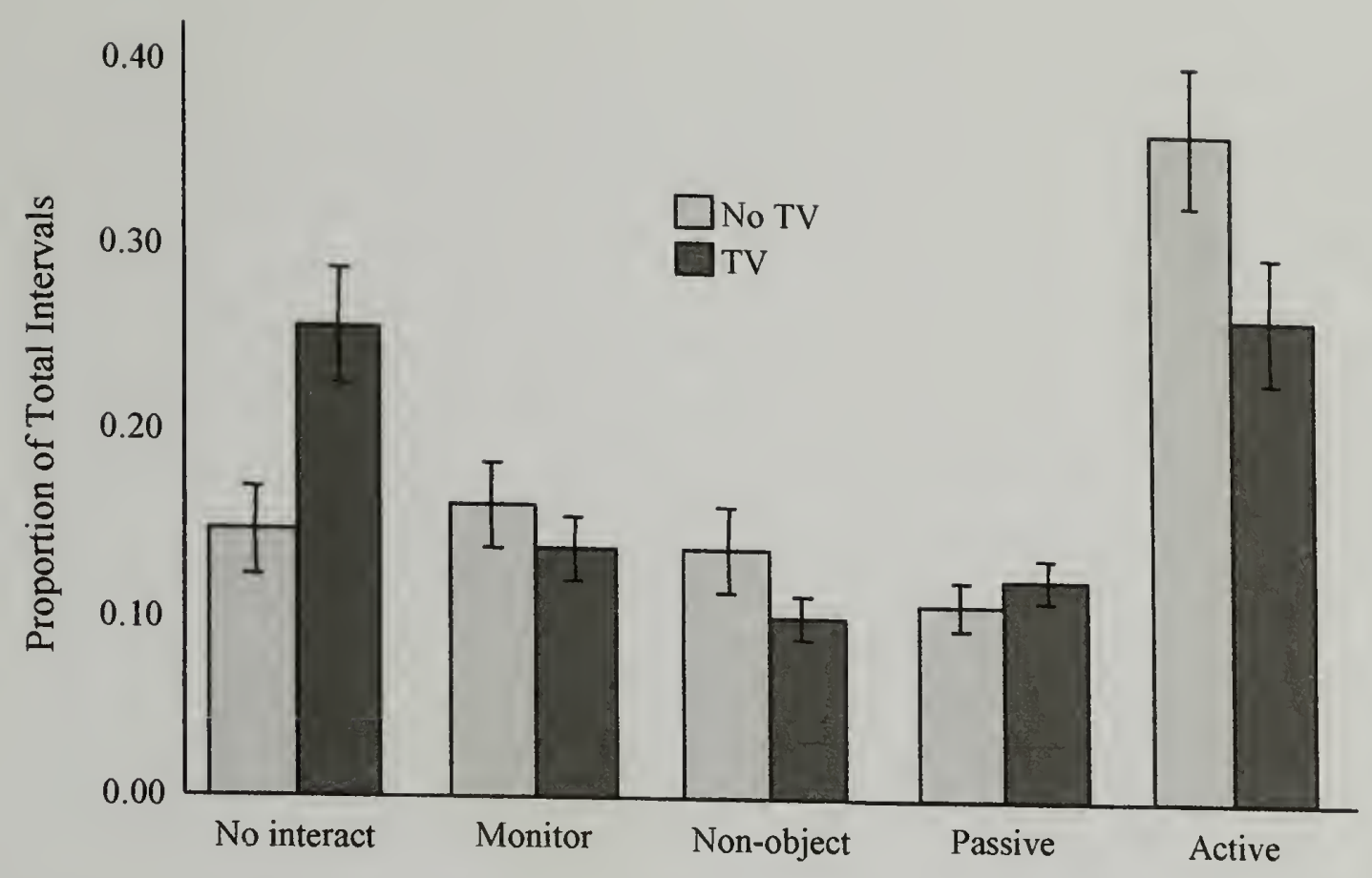

Figure 6. Proportion of intervals containing each of the five original levels of involvement in the No TV and TV conditions. Bars represent $+/$ - one standard error.

Total time interacting was the proportion of total intervals coded as passive, active, or non-object play. Because all behaviors in this category were mutually exclusive (i.e., each interval was designated one and only one code), the remaining proportion was exactly the amount of time not interacting and therefore not necessary to analyze separately. Total object play was the proportion of total intervals in which the parents were engaged in either passive or active toy play. Relative active object play was the proportion of time spent in object play during which parents were actively involved (i.e., the number of active intervals divided by total object play). See Table 10 for proportions with and without background television for all dependent measures in this category. 
Figure 6 presents the mean proportion of intervals in the No TV and TV conditions for the five original levels of involvement. The only significant main effects of television on these behaviors were for not interacting and active object play, $F(1,27)$ $=11.69, p<.01(\mathrm{MSE}=.22)$, and $F(1,27)=13.26, p<.01(\mathrm{MSE}=.17)$, respectively. Parents were more likely to be coded as not interacting when the television was on (26\% versus $14 \%$ ) and less likely to be engaged in active object play ( $26 \%$ versus $36 \%$ ). Furthermore, the negative impact of television on active object play was stronger for those who had the television condition in the second half-hour, $F(1,27)=7.79, p=.01$ $(\mathrm{MSE}=.10 ;$ see Table 11).

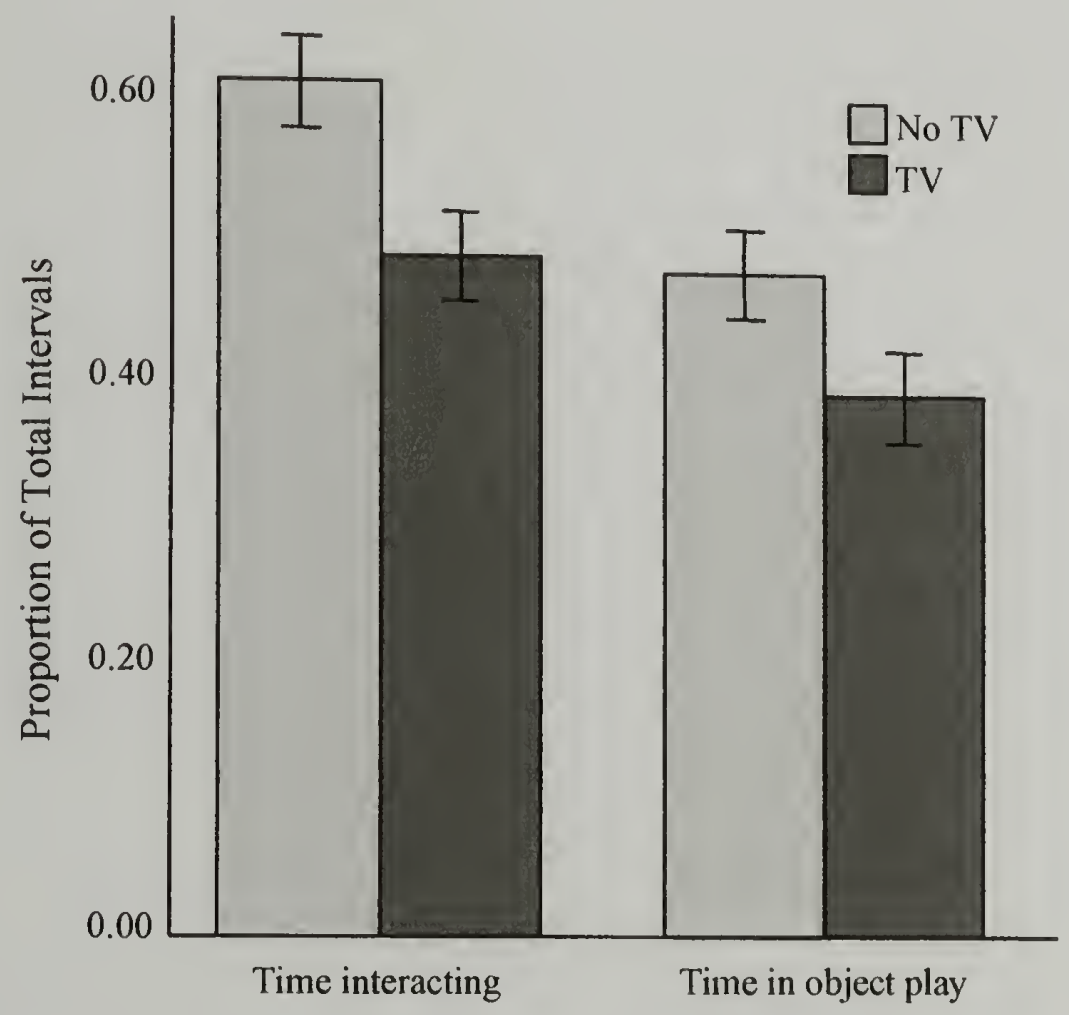

Figure 7. Proportion of total time spent interacting or engaged in object play in the No TV and TV conditions. Bars represent $+/$ - one standard error. 
The overall amount of time spent interacting and engaged in toy play was substantially reduced with television, $F(1,27)=15.76, p<.01(\mathrm{MSE}=.27)$, and $F(1$, $27)=7.94, p<.01(\mathrm{MSE}=.12)$, respectively. Parents spent approximately $61 \%$ of the No TV session interacting with their children ( $47 \%$ object play) compared to $48 \%$ of the time when the television was on ( $38 \%$ object play). Furthermore, the amount of object play in which parents were actively involved decreased from $73 \%$ without television to $62 \%$ in the TV condition, $F(1,27)=12.61, p<.01(\mathrm{MSE}=.21)$. See Figure 7 for mean proportion of total intervals spent interacting or engaged in object play. 


\section{CHAPTER 4}

\section{DISCUSSION}

\section{Overall Parent Interaction and Responsiveness}

Background television has a negative impact on the frequency of parent-child interaction. In particular, even though parents were not given specific instructions to watch the television program, they were much less verbally interactive with their children when the television was on compared to when it was off. The present study found a $17 \%$ decrease in overall verbal interaction on the part of the parent, equating to approximately 10 minutes per hour of background television. In light of this finding, if the six hours of television exposure per day in American homes (Kaiser Family Foundation, 1999) were as background, children would be losing nearly an hour each day talking to their parents. Assuming young children only have about 14 hours of waking time per day this would result in almost an entire month of lost parent-child interaction annually.

The impact of television on absolute frequencies of behaviors appears to depend on how often the behavior occurs. Although regression to the mean cannot be ruled out entirely as an explanation for this finding, there is some evidence to suggest that television had a stronger impact on the behavior of more interactive parents than on parents with a relatively low interaction rate. This trend also appeared within categories of behaviors, such that the more frequent behaviors decreased more with television than less common ones. At least in the current sample, it was the case that the behaviors considered to be positive (e.g., asking questions, suggesting rather directing activities, 
maintaining attention) were substantially more common than their less positive counterparts (e.g., restricting play and redirecting attention). As a result, television not only decreased overall interaction, but increased the occurrence of negative behaviors in relation to positive ones. The impact of television on the quality of parent behaviors will be discussed further in the next section.

Wachs (1986) proposed that background noise may interfere with parent-child interaction by interrupting verbal processing and therefore the parent's ability to verbally stimulate his or her child. While this view was clearly supported in the present study, it is also important that the negative effect of television on parent interaction was not limited to verbal stimulation. The parent involvement scale differed from the verbal interaction measure in two important ways. First, this measure did not limit parents' involvement to how often they spoke to their children, thereby taking into account behavior not captured by the verbal interaction coding. For example, a parent who was sitting on the floor and building a tower with blocks alongside his or her child would not have been coded as interacting in the first measure unless the two were verbally interacting as well. Using the involvement scale, however, the same parent would be considered actively involved during toy play. The second major advantage inherent in the involvement scale was that it provided a more general measure of parents' behavior. For verbal stimulation, parents were coded as interacting if they made any utterance in a given interval. The involvement scale, however, distinguished between brief, passive acknowledgements of the child and more interested, active encouragement of play. Using this scale, there was a $20 \%$ decrease in the amount of time parents spent interacting in any way with their children with television. This effect is fairly 
comparable to the $17 \%$ decrease seen in verbal interactions. The somewhat larger effect on overall involvement is likely due to the decrease in nonverbal toy play that was not accounted for by the first coding scheme.

With regard to responsiveness, there appears to be some evidence in support of the hypothesis that parents become less responsive when the television is on. Although the main effect of television on parent responsiveness was only marginal, it is important to note that the rate of responding was relatively high in both the No TV and TV conditions ( $87 \%$ and $79 \%$, respectively). It may be the case that parents were artificially high in their responsiveness within a laboratory setting, and that home observations would reveal more variable probabilities of responding. Although children's responsiveness was expected to be related to that of their parents, it is not too surprising that an adult television program did not have a negative impact on the responsiveness of children in the present study. This finding supports the hypothesis that an adult television program would have a stronger effect on the behavior of parents. It is important to note, however, that parents in this study were generally more responsive than children and that television may simply have a greater effect on individuals with higher baseline responsiveness.

\section{Quality of Parent Interactions}

Background television affects not only the quantity of parent-child interaction, but also the quality of those interactions that do exist with television. In general, parents were less likely to be attentive and actively involved during interactions with their children in the presence of television. In addition to a significant drop in the 
overall amount of joint object play, parents became less involved in the play that did exist with television. There was a $15 \%$ decrease in the proportion of object play during which parents were actively engaged rather than passively responsive. This finding lends support to the hypothesis that background television has a differential effect on behaviors requiring relatively more attention on the part of the parent.

With respect to verbal interactions, television appears to have a stronger negative effect on the absolute frequencies of those behaviors that require some sensitivity to the child's activity. These are also the behaviors found in the literature to positively influence development. In particular, informative and suggestive behaviors showed more diramatic reductions than restrictive behaviors, which provide the child little autonomy during play. Similarly, background television had a stronger impact on behaviors that maintained or elaborated upon the child's concurrent focus of attention than those that attempted to redirect it. One caution in interpreting these results is that restrictive and interrupting behaviors were also less frequent than suggestive and attention-following behaviors, and that once again television had a more deleterious effect on the absolute frequencies of more common behaviors. It is possible that a floor effect is present such that the negative behaviors were already extremely uncommon without television, leaving little room for a decrease. Indeed, the reduction in behaviors relative to baseline frequency was actually greater for restrictive and interrupting behaviors. Despite this fact, the relative frequency of negative (i.e., restrictive, interrupting) behaviors to positive (i.e., informative, suggestive, attention-following) ones was higher when television was on in the background. 
Contrary to a priori predictions, television had the strongest impact on parents' responses to child social behaviors, and did not significantly influence parents' spontaneous, self-initiated behaviors. One problem in interpreting this result, however, is in the definitions of the behaviors. Children significantly decreased behavior directed toward the parent with television. As a result, there was less opportunity for parents to respond to children. However, children increased self-directed speech with television. Following the same logic, one would expect unsolicited behavior, which was spontaneous on the part of the parent but related to the child's activity, to also increase in the presence of television, but this was not the case. In fact, unsolicited behavior showed the greatest relative decrease with television. Generally, then, television had a negative effect on parents' behaviors that were related to their children's play but not on completely spontaneous comments.

\section{Child Behavior}

Although television had the predicted effect on children's behavior (i.e., decreasing social behavior and increasing self-directed speech), this effect was largely accounted for by parents' verbal interaction. As expected, children's social behaviors were highly related to parents' verbal interactions. Conversely, the less interactive parents were the more self-directed speech children demonstrated. The overall decrease in social behaviors in the presence of television was relatively comparable for parents $(17 \%)$ and children (19\%). However, it is difficult to determine the full extent to which television was influencing the children through reductions in parent interaction as opposed to a direct effect it may have had on their behavior. 
Although the amount of time children spent in solitary play was not directly measured in the present study, it is likely that the increase in self-directed, objectoriented speech was the result of less social and more solitary toy play. Furthermore, although children's time engaged in social speech decreased with television while selfdirected speech increased, one did not directly replace the other. Children interacted with parents about 7.2 minutes per hour less with television, but only increased selfdirected speech by 2.4 minutes per hour. It is difficult within the context of this study to determine what replaced the rest of the time during which children were not interacting with parents, but possible explanations could be watching television, engaging in focused attention in which children intently and silently examine objects, or simply doing nothing. Further coding and analysis of the data used in this study will provide more information regarding the quantity and quality of children's solitary play behaviors, shedding light on what occupies their time when not interacting with parents.

\section{Child Age and Sex}

Although previous research suggests that parents exhibit different types of verbal behavior toward males and females, there were no clear differences on the basis of sex in the present study. Furthermore, the impact of television on parent-child interaction did not vary as a function of sex. As predicted, older children were more responsive to parents' requests and suggestions and, if parents' verbal interactions were controlled for, older children were more verbally interactive than their younger counterparts. Another trend that arose with respect to age was that background television seems to have a stronger negative impact on the parents of younger children. 
In general, parents were less responsive to the younger children in this sample and more intrusive to their play (i.e., gave more directives and were more likely to redirect their attention). This is not extremely surprising in that parents were more likely to initiate and guide interactions with their less verbal and skilled younger children in play. Additionally, however, the decreases in certain types of behaviors with television were stronger for 24-month-olds. There is some evidence to suggest that parents were generally more verbally interactive with their 24 -month-olds. As a result, the age differences found for the impact of television may simply be another case of baseline frequency. Alternatively, it is possible that 24 -month-olds were more demanding of their parents and required more attention, rendering the television a more seductive distracter to parents. In either case, there may be a developmental trend such that background television has a more deleterious effect on the interactions between parents and younger children.

\section{Impact of Background Television over Time}

There was partial support for the hypothesis that television would have a stronger impact on those who had the TV condition second. In particular, the decreases in suggestive comments and in active involvement during play were more dramatic when the television condition followed 30 minutes of play without television than if it was presented in the first half-hour of the session. Furthermore, parents were generally more actively involved and asked more questions at the beginning of the hour, regardless of condition. In light of these findings, it appears that the predicted effect of parent fatigue occurred, not surprisingly, for the most demanding behaviors. 


\section{Future Directions}

As aforementioned, further coding and analyses of this data will examinc the quantity and quality of children's object play in relation to television and social interaction with parents. Previous research suggests that children's play bccomcs more focused (Lawson, Parincllo, \& Ruff, 1992) and sophisticated (Alessandri, 1992) when playing with a parent. If this is the case, the decrease in focused attention associated with background television found in recent research (Evans et al, 2004a; 2004b) may be exacerbated by the decrease in parent-child interaction found in the present study. Furthermore, Evans and colleagues (2004a; 2004b) did not find an effect of television on play maturity when children played alone. However, given the dccrease in parentchild interaction with television found in the present study, an effcct of television on play sophistication may be found when that aspect of play is eventually coded.

Although in the present study background television had a strong negative effect on average, it is clear from the scattcr plot of the data that the cffect varied widely across dyads, and did not exist at all for some. Further analysis of this dataset will take into account background variables such as socioeconomic status and how often the children are exposed to television at home. Another prcdictor of interest is the content of the background programs. Parents selected a video from a wide range of shows, some of which had a stronger emphasis on storyline and character development, such as the situation comedies, as compared to others, such as the game show or the home repair show. It is possible that the former require more attention on the part of the viewer in order to follow the story and are therefore more detrimental to social interaction. 
It is important to determine the direct impact that television has on parents and children separately, as well as the indirect influence it has through its effect on the other. Children may reduce their interactions with parents entirely because they are responding to their parents' lack of interaction. Conversely, television may render children more likely to engage in solitary play because they need to focus more intently on their activity and as a result parents interact with them less often. Very likely it is a combination of the two, and the inter-relatedness of parent and child social behaviors is responsible for the impact of television seen in the present study.

Future research should also expand the present findings to younger clildren to further investigate the developmental trend suggested here. Data for 12-month-olds are currently being collected and will be subjected to the same coding. Results from this age group will be combined with the 24 - and 36-month-olds to investigate developmental trends in parent-child interaction, toy play, and the impact of background television.

An important generalization can be made regarding the present findings in that they may extend to many other situations in the homes of young children. Parents are often dividing their attention between their children and other activities, such as television viewing, household chores, talking on the telephone, and reading the newspaper, to name a few. Magazines and newspapers provided an unexpected source of information in the present study that may be used to address the question of generalizability. Reading materials were provided for the parent to more effectively replicate the home environment, but in fact many parents spent a substantial amount of time reading these materials, both with and without television. Impressionistically, 
parents seemed less responsivc while reading and more passive in their interactions. These effects may be substantially more dramatic when reading in front of the television because parents need to select out noise from the television, and consequently their children, as distracters from reading. An additional pass through the tapes identifying when parents were reading could revcal important gencralized effects of secondary activities on parent-child interaction as well as the potentially multiplicative effects of "triple-tasking" (i.e., interacting with a child while attempting to read with television on in the background).

Finally, it will be important to replicate these findings within the home. It is likely that an entire hour in which parents are free to play with their children without household chores or leisure activities as distractions is relatively uncommon for many parents. Although there was some variability between individual parent-child dyads, many of the parents in this sample were highly involved and responsive. For example, the task of trying to identify particular clips from the videotapes to illustrate the impact of television on parents' responsiveness was virtually impossible because it was difficult to identify any particular instance where parents werc deliberately watching television and ignoring their children as they demanded attention. It is possible that parents were attempting to be particularly attentive in a novel setting while being observed. In their own homes, however, parents are likely to become involved in other activities and to act more natural. One explanation for the television effect found in the present study may be that parents were simply more inclined to leave their children be when they were contentedly playing alone. Impressionistically, parents seemcd more likely to leave their children to their own devices in the presence of television, even if it 
meant they chose to read a magazine rather than watch the program. In this sense, the television condition may have been the true baseline, rendering parents more natural in their behavior and artificially inflating interaction when the television was off.

\section{Summary and Conclusions}

This study is an important first step in identifying the impact that background television has on interactions between parents and very young children, which may in part explain the negative relationship between early exposure to television and subsequent development. Parents are less interactive, attentive, and responsive in the presence of television. They spend less overall time talking with their children, and engage in less toy play. During what play does exist in the presence of television, parents are proportionately less actively involved.

Although parents could not be coded for looking at the television because they were not always on screen, it is clear from watching the videotapes that decreased interaction cannot entirely be explained by parents actively watching the television program. As mentioned above, it was difficult to find shots on the tapes in which parents were unresponsive to their child's explicit requests specifically because they were watching television. Parents were often coded as passively involved or not interacting while they were attending to activities other than the television, such as reading or cleaning up. Furthermore, parents were not coded as "not interacting" for brief (less than three-second) looks at the screen. It is not surprising that television, given its verbal nature, interferes with parents' verbalizations and responsiveness (Wachs, 1986), but the effect of background television appears to generalize beyond 
verbal interaction. Rather, television seems to render parents generally less able to attend to their children and their activities, even when the parents are not actively watching the program.

The present study has identified one way that background television can have an impact on children's home environments, which can in turn influence development. In light of previous studies regarding the relationship between parent-child interaction and subsequent development, parents around the country may be inadvertently hindering their children's development by assuming that only the shows their children actively watch can affect them. As a result, the present study has implications for intervention and parent education. 


\section{APPENDIX A}

\section{CAREGIVER QUESTIONNAIRE}

\section{Personal Information}

1. Which best describes the highest level of education you and your child's other parent have completed?
You: High School
Other: High School
Some College
Some College
College
Graduate School
College Graduate School

2. What is your current occupation? Other parent?

3. What is your child's ethnicity? Circle all that apply.

White/Caucasian Black Hispanic Asian
American Indian Cape Verdean
Other (please specify)

4. How many siblings does your child have in the home?

5. Does your child have any vision or hearing difficulties?

Yes No If yes, please describe

Television Viewing Information

1. Does your child ever ask to have the television turned on?

Yes No

2. Does your child ever turn on the television by herself/himself?

Yes No

3. Does your child change the channel by herself/himself?

Yes No

4. Does your child ever ask to see a particular TV program?

Yes No

5. What TV program (if any) is your child's current favorite?

6. When your child watches a TV program, how often does your child watch attentively?
A Little
Sometimes
Most of the Time
Always 
7. Do you sometimes encourage your child to watch television or videos? Yes No

8. In a typical day, how many hours does your child watch videos on the VCR?

9. When your child watches videos on the VCR, how often does your child watch attentively?
A Little
Sometimes
Most of the Time
Always

10. What are your child's favorite videos?

On this grid, please mark when your child is home during a typical weekday (Monday through Friday), by placing an X in the box marked home. On the same grid, please mark when your child is exposed to television, (meaning that he or she is in the room when the TV or VCR is on) by placing an X in the box marked "child exposed to TV." This would include times when someone else is the primary person watching.

\begin{tabular}{|c|c|c|c|c|c|}
\hline Time & $\begin{array}{c}\text { Child } \\
\text { at home }\end{array}$ & $\begin{array}{c}\text { Child } \\
\text { exposed to TV }\end{array}$ & Time & $\begin{array}{c}\text { Child } \\
\text { at home }\end{array}$ & $\begin{array}{c}\text { Child } \\
\text { exposed to TV }\end{array}$ \\
\hline 6:00 AM & & & $5: 00 \mathrm{PM}$ & & \\
\hline 7:00 AM & & & $6: 00 \mathrm{PM}$ & & \\
\hline 8:00 AM & & & $7: 00 \mathrm{PM}$ & & \\
\hline 9:00 AM & & & $8: 00 \mathrm{PM}$ & & \\
\hline 10:00 AM & & $9: 00 \mathrm{PM}$ & & \\
\hline $11: 00 \mathrm{AM}$ & & & $10: 00 \mathrm{PM}$ & & \\
\hline $12: 00 \mathrm{PM}$ & & & $11: 00 \mathrm{AM}$ & & \\
\hline $1: 00 \mathrm{PM}$ & & & $12: 00 \mathrm{AM}$ & & \\
\hline 2:00 PM & & & $1: 00 \mathrm{AM}$ & & \\
\hline $3: 00 \mathrm{PM}$ & & & $2: 00 \mathrm{AM}$ & & \\
\hline $4: 00 \mathrm{PM}$ & & & & & \\
\hline
\end{tabular}


Please indicate the same as above for a typical weekend day (Saturday or Sunday).

\begin{tabular}{|c|c|c|c|c|c|}
\hline Time & $\begin{array}{c}\text { Child } \\
\text { at home }\end{array}$ & $\begin{array}{c}\text { Child } \\
\text { exposed to TV }\end{array}$ & Time & $\begin{array}{c}\text { Child } \\
\text { at home }\end{array}$ & $\begin{array}{c}\text { Child } \\
\text { exposed to TV }\end{array}$ \\
\hline 6:00 $\mathrm{AM}$ & & & $5: 00 \mathrm{PM}$ & & \\
\hline 7:00 AM & & & $6: 00 \mathrm{PM}$ & & \\
\hline $8: 00 \mathrm{AM}$ & & & $7: 00 \mathrm{PM}$ & & \\
\hline 9:00 AM & & & $8: 00 \mathrm{PM}$ & & \\
\hline $10: 00 \mathrm{AM}$ & & & $9: 00 \mathrm{PM}$ & & \\
\hline $11: 00 \mathrm{AM}$ & & & $10: 00 \mathrm{PM}$ & & \\
\hline $12: 00 \mathrm{PM}$ & & & $11: 00 \mathrm{AM}$ & & \\
\hline $1: 00 \mathrm{PM}$ & & & $12: 00 \mathrm{AM}$ & & \\
\hline $2: 00 \mathrm{PM}$ & & & $1: 00 \mathrm{AM}$ & & \\
\hline $3: 00 \mathrm{PM}$ & & & $2: 00 \mathrm{AM}$ & & \\
\hline $4: 00 \mathrm{PM}$ & & & & & \\
\hline
\end{tabular}

Please circle which of these toys, in the room, that your child has at home. Only circle the toy if your child has the same toy or a highly similar one.

Toy phone

Baby doll

Stacking cups

Puzzles

Plastic book

Tea set with toy pots and pans

Fisher Price Little People School Bus
Teddy bear

Blocks

Rings

Big truck with big Legos

Shape sorter

Broom

Jack-in-the-box 
Please mark when your child actually watches television programs in a typical week by writing in the name of the show he or she watches in the appropriate day and time slot. The rest of the weekdays will appear on the grid on the next page.

\begin{tabular}{|c|c|c|c|c|}
\hline Time & Monday & Tuesday & Wednesday & Thursday \\
\hline 6:00 AM & & & & \\
\hline $6: 30 \mathrm{AM}$ & & & & \\
\hline 7:00 AM & & & & \\
\hline 7:30 AM & & & & \\
\hline $8: 00 \mathrm{AM}$ & & & & \\
\hline $8: 30 \mathrm{AM}$ & & & & \\
\hline $9: 00 \mathrm{AM}$ & & & & \\
\hline $9: 30 \mathrm{AM}$ & & & & \\
\hline $10: 00 \mathrm{AM}$ & & & & \\
\hline $10: 30 \mathrm{AM}$ & & & & \\
\hline 11:00 AM & & & & \\
\hline $11: 30 \mathrm{AM}$ & & & & \\
\hline 12:00 PM & & & & \\
\hline $12: 30 \mathrm{PM}$ & & & & \\
\hline 1:00 PM & & & & \\
\hline 1:30 PM & & & & \\
\hline 2:00 PM & & & & \\
\hline 2:30 PM & & & & \\
\hline 3:00 PM & & & & \\
\hline 3:30 PM & & & & \\
\hline 4:00 PM & & & & \\
\hline 4:30 PM & & & & \\
\hline 5:00 PM & & & & \\
\hline $5: 30 \mathrm{PM}$ & & & & \\
\hline 6:00 PM & & & & \\
\hline 6:30 PM & & & & \\
\hline 7:00 PM & & & & \\
\hline 7:30 PM & & & & \\
\hline 8:00 PM & & & & \\
\hline 8:30 PM & & & & \\
\hline 9:00 PM & & & & \\
\hline 9:30 PM & & & & \\
\hline 10:00 PM & & & & \\
\hline 10:30 PM & & & & \\
\hline 11:00 PM & & & & \\
\hline 11:30 PM & & & & \\
\hline $12: 00 \mathrm{AM}$ & & & & \\
\hline $12: 30 \mathrm{AM}$ & & & & \\
\hline 1:00 AM & & & & \\
\hline $1: 30 \mathrm{AM}$ & & & & \\
\hline
\end{tabular}




\begin{tabular}{|c|c|c|c|}
\hline Time & Friday & Saturday & Sunday \\
\hline \multicolumn{4}{|l|}{$\frac{6: 00 \mathrm{AM}}{6.30 \mathrm{MM}}$} \\
\hline \multicolumn{4}{|l|}{$\frac{6: 30 \mathrm{AM}}{7: 00 \mathrm{AM}}$} \\
\hline \multicolumn{4}{|l|}{$\frac{7: 00 \mathrm{AM}}{7: 30 \mathrm{AM}}$} \\
\hline \multicolumn{4}{|l|}{$\frac{7: 30 \mathrm{AM}}{8.00 \mathrm{AM}}$} \\
\hline \multicolumn{4}{|l|}{$\frac{8: 00 \mathrm{AM}}{8.30 \mathrm{AM}}$} \\
\hline \multicolumn{4}{|l|}{$8: 30 \mathrm{AM}$} \\
\hline \multicolumn{4}{|l|}{ 9:00 AM } \\
\hline \multicolumn{4}{|l|}{$9: 30 \mathrm{AM}$} \\
\hline \multicolumn{4}{|l|}{ 10:00 AM } \\
\hline \multicolumn{4}{|l|}{ 10:30 AM } \\
\hline \multicolumn{4}{|l|}{ 11:00 AM } \\
\hline \multicolumn{4}{|l|}{ 11:30 AM } \\
\hline \multicolumn{4}{|l|}{ 12:00 PM } \\
\hline \multicolumn{4}{|l|}{ 12:30 PM } \\
\hline \multicolumn{4}{|l|}{ 1:00 PM } \\
\hline \multicolumn{4}{|l|}{ 1:30 PM } \\
\hline \multicolumn{4}{|l|}{ 2:00 PM } \\
\hline \multicolumn{4}{|l|}{ 2:30 PM } \\
\hline \multicolumn{4}{|l|}{ 3:00 PM } \\
\hline \multicolumn{4}{|l|}{ 3:30 PM } \\
\hline \multicolumn{4}{|l|}{ 4:00 PM } \\
\hline \multicolumn{4}{|l|}{ 4:30 PM } \\
\hline \multicolumn{4}{|l|}{ 5:00 PM } \\
\hline \multicolumn{4}{|l|}{ 5:30 PM } \\
\hline \multicolumn{4}{|l|}{ 6:00 PM } \\
\hline \multicolumn{4}{|l|}{ 6:30 PM } \\
\hline \multicolumn{4}{|l|}{ 7:00 PM } \\
\hline 7:30 PM & & & \\
\hline 8:00 PM & & & \\
\hline $8: 30 \mathrm{PM}$ & & & \\
\hline 9:00 PM & & & \\
\hline 9:30 PM & & & \\
\hline 10:00 PM & & & \\
\hline 10:30 PM & & & \\
\hline 11:00 PM & & & \\
\hline 11:30 PM & & & \\
\hline $12: 00 \mathrm{AM}$ & & & \\
\hline $12: 30 \mathrm{AM}$ & & & \\
\hline 1:00 AM & & & \\
\hline $1: 30 \mathrm{AM}$ & & & \\
\hline
\end{tabular}




\section{APPENDIX B}

SAMPLE CODING SHEET

\begin{tabular}{|c|c|c|c|c|c|c|c|}
\hline & \multicolumn{3}{|c|}{ Mother's Behavior } & \multicolumn{3}{|c|}{ Child's Behavior } \\
\hline Start & Type & Strategy & Atten-Dir & Involve & Type & Resp & Request \\
\hline $0: 00: 00$ & & & & & & & \\
\hline $0: 00: 10$ & & & & & & & \\
\hline $0: 00: 20$ & & & & & & & \\
\hline $0: 00: 30$ & & & & & & & \\
\hline $0: 00: 40$ & & & & & & & \\
\hline $0: 00: 50$ & & & & & & & \\
\hline $0: 01: 00$ & & & & & & & \\
\hline $0: 01: 10$ & & & & & & & \\
\hline $0: 01: 20$ & & & & & & & \\
\hline $0: 01: 30$ & & & & & & & \\
\hline $0: 01: 40$ & & & & & & & \\
\hline $0: 01: 50$ & & & & & & & \\
\hline $0: 02: 00$ & & & & & & & \\
\hline $0: 02: 10$ & & & & & & & \\
\hline $0: 02: 20$ & & & & & & & \\
\hline $0: 02: 30$ & & & & & & & \\
\hline $0: 02: 40$ & & & & & & & \\
\hline $0: 02: 50$ & & & & & & & \\
\hline $0: 03: 00$ & & & & & & & \\
\hline $0: 03: 10$ & & & & & & & \\
\hline $0: 03: 20$ & & & & & & & \\
\hline $0: 03: 30$ & & & & & & & \\
\hline $0: 03: 40$ & & & & & & & \\
\hline $0: 03: 50$ & & & & & & & \\
\hline $0: 04: 00$ & & & & & & & \\
\hline $0: 04: 10$ & & & & & & & \\
\hline $0: 04: 20$ & & & & & & & \\
\hline $0: 04: 30$ & & & & & & & \\
\hline $0: 04: 40$ & & & & & & & \\
\hline $0: 04: 50$ & & & & & & & \\
\hline $0: 05: 00$ & & & & & & & \\
\hline $0: 05: 10$ & & & & & & & \\
\hline $0: 05: 20$ & & & & & & & \\
\hline $0: 05: 30$ & & & & & & & \\
\hline $0: 05: 40$ & & & & & & & \\
\hline $0: 05: 50$ & & & & & & & \\
\hline $0: 06: 00$ & & & & & & & \\
\hline $0: 06: 10$ & & & & & & & \\
\hline $0: 06: 20$ & & & & & & & \\
\hline & & & & & & & \\
\hline
\end{tabular}




\section{BIBLIOGRAPHY}

Alessandri, S.M. (1992). Mother-child interactional correlates of maltreated and nonmaltreated children's play behavior. Development \& Psychopathology, 4, 257-270.

American Academy of Pediatrics, Committee on Public Education (1999). Media education. Pediatrics, 104, 341-342.

Anderson, D.R. \& Evans, M.K. (2001). Peril and potential of media for infants and toddlers. Zero to three: National Center for Infants, Toddlers, and Families, 22, $10-16$.

Anderson, D.R., Huston, A.C., Schmitt, K.L., Linebarger, D.L. \& Wright, J.C. (2001). Early childhood television viewing and adolescent behavior: The recontact study. Monographs of the Society for Research in Child Development. 68 , Serial No. 264, 1-143.

Armstrong, G.B., Greenberg, B.S. (1990). Background television as an inhibitor of cognitive processing. Human Communication Research, 16, 355-386.

Baker, M.A., \& Holding, D.H. (1993). The effects of noise and speech on cognitive task performance. The Journal of General Psychology, 120, 339-355.

Beckwith, L., \& Rodning, C. (1996). Dyadic processes between mothers and preterm infants: Development at ages 2 to 5 years. Infant Mental Health Journal, 17, 322-333.

Bornstein, M.H., \& Tamis-LeMonda, C.S. (1989). Maternal responsiveness and cognitive development in children. In M. H. Bornstein (Ed.), Maternal Responsiveness: Characteristics and Consequences (pp. 49-61). San Francisco, CA: Jossey-Bass.

Burns, J.J., \& Anderson, D.R. (1993). Attentional inertia and recognition memory in adults' television viewing. Communication Research, 20, 777-799.

Carew, J.V. (1980). Experience and the development of intelligence in young children at home and in day care. Monographs for the Society for Research in Child Development, 45, Serial No. 187. Chicago: University of Chicago Press.

Christakis, D.A., Zimmerman, F.J., DiGiuseppe, D.L., \& McCarty, C.A. (2004). Early television exposure and subsequent attentional problems in children. Pediatrics, $113,708-713$. 
Clarke-Stewart, K.A. (1973). Interactions between mothers and their young children: Characteristics and Consequences. Monographs of the Society for Research in Child Development, 38, Serial No. 153.

Corapci, F., \& Wachs, T.D. (2000). Does parental mood or efficacy mediate the influence of environmental chaos upon parenting behavior? Merril-Palmer Quarterly, 48, 182-201.

Crowley, K., Callanan, M.A., Jipson, J.L., Galco, J., Topping, K., \& Shrager, J. (2001). Shared scientific thinking in everyday parent-child activity. Science Education, $85,712-732$.

Evans, M.K., Frankenfield, A.F., Pempek, T.A, Kirkorian, H.L., \& Anderson, D.R. (2004a). The impact of background television on very young children. Manuscript in progress for publication.

Evans, M.K., Pempek, T.A., Kirkorian, H.L., Frankenfield, A.E., \& Anderson, D.R. (2004b, May). The impact of background television on complexity of play. Poster session presented at the biannual International Conference for Infant Studies, Chicago, IL.

Garner, P.W., \& Landry, S.H. (1994). Effects of maternal attention-directing strategies on preterm infants' affective expressions during joint toy play. Infant Behavior \& Development, 17, 15-22.

Garner, P.W., Rennie, K.M., \& Miner, J.L. (1996). Sharing attention to toys: Adolescent mother-toddler dyads. Early Development \& Parenting, 5, 101-110.

Henderson, B.B. (1984). Parents and exploration: The effect of context on individual differences in exploratory behavior. Child Development, 55, 1237-1245.

Kaiser Family Foundation (1999). Kids \& media @ the new millennium: A comprehensive national analysis of children's media use. Menlo Park: The Henry J. Kaiser Family Foundation.

Kaiser Family Foundation (2003). Zero to six: Electronic media in the lives of infants, toddlers, and preschoolers. Menlo Park: The Henry J. Kaiser Family Foundation.

Laasko, M.L., Poikkeus, A.M., Eklund, K., \& Lytinen, P. (1999). Social interactional behaviors and symbolic play competence as predictors of language development and their associations with maternal attention-directing strategies. Infant Behavior and Development, 22, 541-556.

Landry, S.H., \& Chapieski, M.L. (1989). Joint attention and infant toy exploration: Effects of Down's syndrome and prematurity. Child Development, 60, 103-118. 
Landry, S.H., Garner, P.W., Pirie, D., \& Swank, P.R. (1994). Effects of social context and mothers' requesting strategies on Down's syndrome children's social responsiveness. Developmental Psychology, 30, 293-302.

Landry, S.H., Miller-Loncar, C.L., \& Swank, P.R. (1998) Goal-directed behavior in children with Down's syndrome: The role of joint play situations. Early Education \& Development, 9, 375-392.

Landry, S.H., Smith, K.E., Miller-Loncar, C.L., \& Swank, P.R. (1998). The relation of change in maternal interactive styles to the developing social competence of full-term and preterm children. Child Development, 69, 105-123.

Landry, S.H., Smith, K.E., Swank, P.R., Assel, M.A., \& Vellet, S. (2001). Does early responsive parenting have a special importance for children's development or is consistency across early childhood necessary? Developmental Psychology, 37, 387-403.

Lawson, K.R., Parrinello, R., \& Ruff, H.A. (1992) Maternal behavior and infant attention. Infant Behavior \& Development, 15, 209-229.

Lewis, M.D. (1993). Early socioemotional predictors of cognitive competency at 4 years. Developmental Psychology, 29, 1036-1045.

Nelson, K. (1973). Structure and strategy in learning to talk. Monographs of the Society for Research in Child Development, 38, Serial No. 149, 1-137.

National Institute of Child Health and Human Development: Early Child Care Research Network (2003). Do children's attention processes mediate the link between family predictors and school readiness? Developmental Psychology, 39, 581593.

Olson, S.L., Bates, J.E., \& Bayles, K. (1984). Mother-infant interaction and the development of individual differences in children's cognitive competence. Developmental Psychology, 20, 166-179.

Parks, P.L., \& Bradley, R.H. (1991). The interaction of home environment features and their relation to infant competence. Infant Mental Health Journal, 12, 3-14.

Parpal, M., \& Maccoby, E.E. (1985). Maternal responsiveness and subsequent child compliance. Child Development, 56, 1326-1334.

Pool, M.M., Koolstra, C.M., \& van der Voort, T.H.A. (2003a). The impact of background radio and television on high school students' homework performance. Journal of Communication, 53, 74-87. 
Pool, M.M., Koolstra, C.M., \& van der Voort, T.H.A. (2003b). Distraction effects of background soap operas on homework performance: An experimental study enriched with observational data. Educational Psychology, 23, 361-380.

Pool, M.M., van der Voort, T.H.A., Beentjes, J.W.J, \& Koolstra, C.M. (2000). Background television as an inhibitor of performance on easy and difficult homework assignments. Communication Research, 27, 293-326.

Rocissano, L., Slade, A., \& Lynch, V. (1987). Dyadic synchrony and toddler compliance. Developmental Psychology, 23, 698-704.

Schmitt, K.L., Woolf, K.D. \& Anderson, D.R. (2003). Viewing the viewers: Viewing behaviors by children and adults during television programs and commercials. Journal of Communication, 53, 265-281.

Shaw, D.S., Keenan, K., \& Vondra, J.I. (1994). Developmental precursors of externalizing behavior: Ages 1 to 3. Developmental Psychology, 30, 355-364.

Slade, A. (1987). A longitudinal study of maternal involvement and symbolic play during the toddler period. Child Development, 58, 367-375.

Stevens, E., Blake, J., Vitale, G., \& MacDonald (1998). Mother-infant object involvement at 9 and 15 months: Relation to infant cognition and early vocabulary. First Language, 18, 203-222.

Tamis-Lemonda, C.S., Bornstein, M.H., Baumwell, L., Damast, A., \& Melstein (1996). Responsive parenting in the second year: Specific influences on children's language and play. Early Development \& Parenting, 5, 173-183.

Vygotsky, L.S. (1978). Mind in society: The development of higher psychological processes. Cambridge, MA: Harvard University Press.

Wachs, T.D. (1986). Ambient background noise and early development. Children's Environments Quarterly, 3, 23-33.

Wright, J.C., Huston, A.C., Murphy, K.C., St. Peters, M., Pinon, M., Scantlin, R., \& Kotler, J (2001). The relations of early television viewing to school readiness and vocabulary of children from low-income families: The early window project. Child Development, 72, 1347-1366. 
